\title{
Recent Advances in Molecularly Imprinted Membranes for Sample Treatment and Separation
}

\author{
Sagrario Torres-Cartas ${ }^{1}$, Mónica Catalá-Icardo ${ }^{1}$, Susana Meseguer-Lloret ${ }^{1}$, \\ Ernesto F. Simó-Alfonso ${ }^{2}$ and José Manuel Herrero-Martínez ${ }^{2, *}$ (i) \\ 1 Instituto de Investigación para la Gestión Integrada de Zonas Costeras, Campus de Gandia, \\ Universitat Politècnica de València, C/Paranimf 1, 46730 Grau de Gandia, Valencia, Spain; \\ sagtorca@qim.upv.es (S.T.-C.); mocaic@qim.upv.es (M.C.-I.); sumello@qim.upv.es (S.M.-L.) \\ 2 Department of Analytical Chemistry, University of Valencia, Dr. Moliner 50, 46100 Burjassot, Valencia, Spain; \\ ernesto.simo@uv.es \\ * Correspondence: jmherrer@uv.es
}

Received: 6 November 2020; Accepted: 28 November 2020; Published: 30 November 2020

check for updates

\begin{abstract}
This review describes the recent advances from the past five years concerning the development and applications of molecularly imprinted membranes (MIMs) in the field of sample treatment and separation processes. After a short introduction, where the importance of these materials is highlighted, a description of key aspects of membrane separation followed by the strategies of preparation of these materials is described. The review continues with several analytical applications of these MIMs for sample preparation as well as for separation purposes covering pharmaceutical, food, and environmental areas. Finally, a discussion focused on possible future directions of these materials in extraction and separation field is also given.
\end{abstract}

Keywords: membrane; molecularly imprinted polymer; polymerization; template; molecular recognition; extraction; permeation; adsorption; separation

\section{Introduction}

Sample treatment is one of the most important stages in chemical analysis. Its role is primarily focused on removing potentially interfering components present in the sample and as well as to preconcentrate the analytes to achieve the desired sensitivity. The most widely used method for the extraction and clean-up of solutes of interest is solid-phase extraction (SPE), which involves the use of stationary phases such as nonpolar polymer or C18-bonded silica. However, these sorbents have limited selectivity, are rather expensive, and designed for single use. To increase selectivity, molecularly imprinted polymers (MIPs) were introduced in recent decades [1,2], thus providing a specific interaction target molecule-polymer, similar to the interactions antigen-antibody in biological systems.

The synthesis of MIPs involves the formation of a template (that is commonly the target analyte)monomer complex with either covalent or non-covalent interactions, followed by copolymerization in the presence of a suitable cross-linker. After removing the template, imprinted cavities of specific size and shape are left inside the polymer network, exhibiting sites with molecular recognition properties for the target molecule.

Attending to the type of interaction between the template molecule and functional monomer, MIPs can be classified in non-covalent, covalent, and semi-covalent imprinting. In the non-covalent approach, the formation of pre-polymerization complex is accomplished via weak non-covalent interactions (van der Waals forces, hydrogen bonding, ionic interactions, etc.). After the synthesis, the template is easily removed from the polymer simply by rinsing with appropriate solvents. This approach is the most widely used, due to its versatility, simplicity, and ease of preparation. In the covalent approach, 
the template and the functional monomer are covalently bound prior to polymerization; however, the removal of the template as well as its posterior rebinding to the cavities is more laborious. On the other hand, the semi-covalent option combines the advantages of both non-covalent and covalent approaches, being the template covalently bound to a functional monomer during polymerization, whereas only non-covalent interactions are exploited during the template rebinding [3,4].

In any case, the resulting MIPs are stable, robust, and resistant to a wide range of $\mathrm{pH}$, solvents and temperature, and exhibit advantages of stability, reusability, ease of use, and low cost of preparation $[5,6]$. Also, they exhibited large selectivity and an enhanced adsorption capability compared to their analogues synthesized in absence of template (NIPs). Indeed, MIPs are currently being used in a wide of analytical applications, including chromatography [7,8], microextraction techniques [7,9-13], and sensing [14].

As we mentioned above, these materials are prepared in different formats. Among the recent MIP supports, the development of MIPs on soft and flexible platforms such as paper or membranes is of great interest [14-16]. In particular, the introduction of molecular recognition sites into membranes to produce molecularly imprinted membranes (MIMs) is highly advantageous since it combines the separation ability of the membranes (due to their pore size) with the great selective recognition ability of the imprinted polymer. The MIM format can favor the mass transfer processes decreasing adsorption/retention time in extraction and separation processes $[14,15,17,18]$. Indeed, MIM separation technology was widely used in the fields of separation and purification, being particularly helpful for large-scale continuous separation operations, especially in industrial applications [14]. However, the extension of MIMs to sample treatment field has been relatively limited.

The present review summarizes and discusses papers published in the last five years to fill this void in analytical science, emphasizing the key role of these supports in the sample treatment field. The review starts with an introduction of membrane media, including the different approaches, from the conventional in situ polymerization to the surface molecular imprinting strategies for the preparation of selective MIMs. Next, the applications of the above-mentioned materials for the extraction or preconcentration of different target compounds in a wide range of matrices are described. Also, recent applications of these promising materials in the separation and purification processes are included, with special emphasis in pharmaceutical, food and environmental field. Finally, a general conclusion as well as expected future trends of MIM media in sample preparation and separation purposes is included.

\section{General Aspects of MIMs and Preparation}

\subsection{Fundamental Aspects in Membrane Separation}

Usually, membrane supports regulate the transport of molecules among phases allowing their separation and purification. In particular, separation capability of membranes is governed by its perm-selectivity, which depends on diffusivity and affinity of the membrane. Diffusion transport mechanism of molecules across the membrane depends on the dimension and/or shape of the given molecule and porosity of the membrane, thus predominating solution-diffusion mechanism for non-porous membranes, and partition-diffusion mechanism for porous membranes (pore size $>1 \mathrm{~nm}$ ) [14,19]. Also, flux is another essential factor in membrane separation processes. Indeed, flux and perm-selectivity often have a trade-off relationship. The compromise is made by the fact that enhancement of the flux through the membrane usually leads to a simultaneous reduction in perm-selectivity and vice versa. Consequently, it is important to increase both factors to produce MIMs with enhanced performance for extraction, purification, and separation purposes.

For this purpose, it is relevant in order to achieve a good MIM performance to control the density and affinity of membrane MIP sites and to create proper membrane pore morphology. Indeed, different mechanisms for selective transport can be regarded. According to Ulbricht et al. [20], two mass separation mechanisms can occur in membranes: One is facilitated permeation that is the preferential diffusion of the target molecule as a result of affinity, whereas the other is retarded permeation owing 
to the affinity binding of the target molecule translating into the faster elution of competitors of the print molecule. These mechanisms are strongly related to morphological features of resulting MIMs. Thus, in MIMs with meso- and micropores, the template binding to imprinted cavities can either change the pore network to alter membrane permeability (the so-called "gate-effect") or a variation of the permeation rate due to the interaction with the micropore walls [19]. On the other hand, in MIMs with trans-membrane macropores, a retarded permeation of the target molecule is held by binding to accessible imprinted sites thus compensating nonselective transport by convection or diffusion [19]. Once we comment on the key aspects of MIMs to be considered in extraction and separation purposes, different strategies to obtain MIMs will be described.

\subsection{Types of Strategies to Synthesize MIMs}

In general, three main strategies can be used for MIM preparation [14,20]: (i) preparation of MIMs from previously synthesized "conventional" MIP particles; (ii) preparation of MIP structure and membrane morphology simultaneously; and (iii) preparation of MIPs on or in a previously synthesized membrane with suited morphology.

In the first approach, different methods were developed for MIP particles production, such as bulk polymerization, precipitation polymerization, suspension polymerization, among others, which were reviewed $[1,21]$. The prepared MIP particles are incorporated to the membrane support by physical mixing or other procedures, giving a membrane with mostly embedded MIP particles. As a result, these membranes showed a low availability of efficient imprinting sites, and consequently, a final limited performance. Besides, the permeability of this type of membranes is relatively low, which limit their applications in affinity separation and extraction purposes. Figure 1 shows an example of this preparation strategy, where the resulting MIMs and non-imprinted membranes (NIMs) were visualized by scanning electron microscopy (SEM). As can be seen, the addition of MIP nanoparticles to cellulose acetate (CA) membrane produced the presence of larger pores (binding sites) within the membrane matrix compared with the NIM [22].

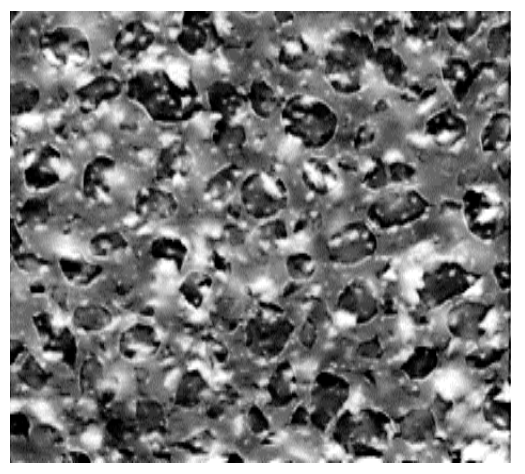

(a)

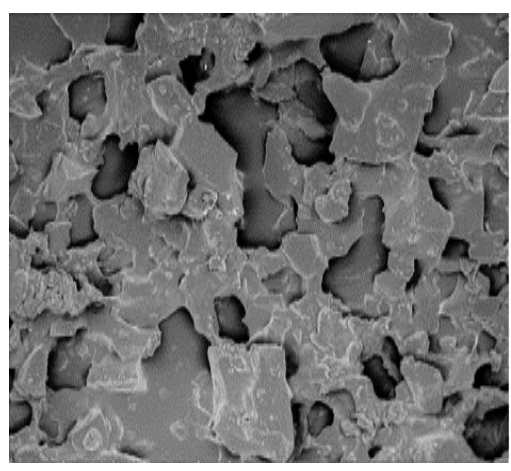

(b)

Figure 1. SEM micrographs showing the surface morphology of MIM prepared by embedding of nanoMIP particles in a CA membrane (a) and its corresponding NIM (b). Reproduced with permission [22].

Concerning the second strategy ("simultaneous MIM preparation"), the control of film thickness, e.g., by solution casting or using molds, is an essential aspect to achieve reproducible and stable flat-sheet membranes. In this sense, when established MIP synthesis protocols are applied, the "synchronization" of imprinting and film solidification steps are of critical importance in controlling the MIM shape, structure, and functionality [14]. In this sense, two main routes were used, the "traditional" in situ cross-linking polymerization and the "alternative" polymer solution phase inversion. Also, NIMs are made following the same procedures but without the presence of template molecule in the casting solution. An example of this strategy was that described by Székely et al. [23], who developed 
nanofiltration membranes with molecular recognition sites by phase inversion molecular imprinting technique. The MIM showed a finger-like macrovoid morphology compared to the NIM (Figure 2), which is an usual characteristic in membranes prepared from nonsolvent-induced phase inversion method [24]. The presence of template-induced binding cavities also led to higher surface area and pore volume values than the NIM.
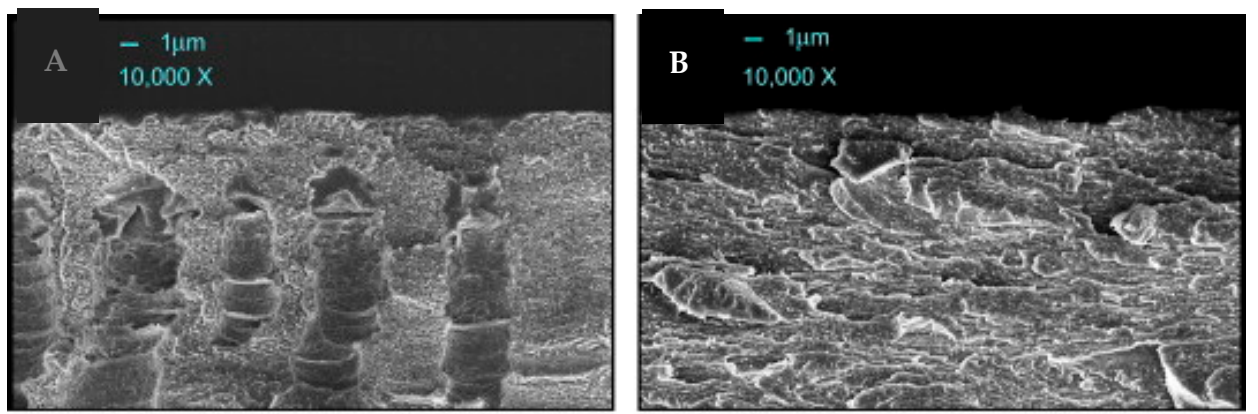

Figure 2. SEM images showing membrane cross-sections of MIM (A) and NIM (B) prepared via phase inversion technique. Reproduced with permission [23].

Although the first route using preestablished MIP preparation protocols for the synthesis of flat-sheet membranes is still being applied, the phase inversion imprinting has become a widely recognized technique in MIM preparation. It consists of the solidification of the polymer accomplished by solvent evaporation or by nonsolvent-induced precipitation. Thus, the polymer selection for phase inversion imprinting had been extended to most of the commonly used membrane materials, e.g., CA, polyacrylonitrile, polyamide, and polysulfone (PSf), among others [14,20]. One reported example of the application of this imprinting technique is given in Figure 3. In particular, He et al. [25] developed a highly selective CA blend imprinted membranes for salicylic acid prepared with sulfonated polysulfone as a functional polymer, polyethylene glycol-4000 and ionic liquid 1-butyl-3-methylimidazolium chloride as additives.

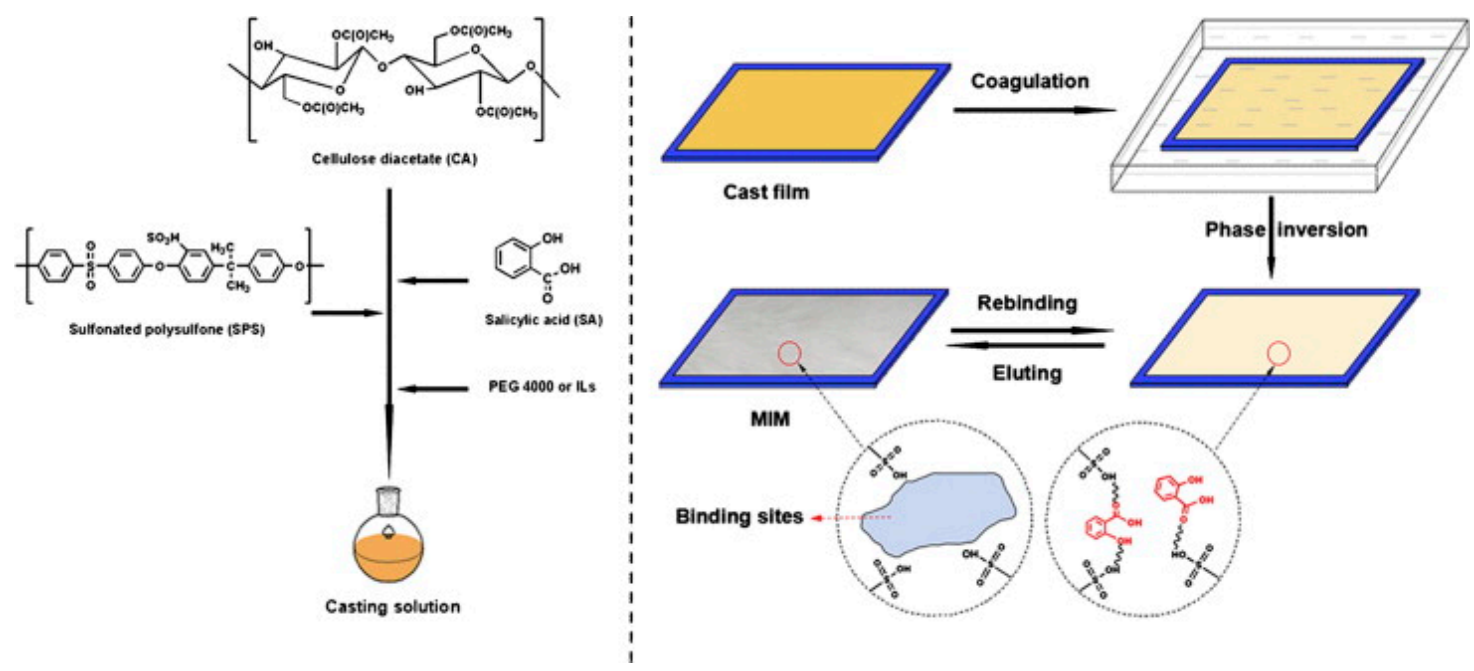

Figure 3. Schematic illustration of preparation of a MIM by phase inversion technique. Reproduced with permission [25].

Despite inherent advantages of this strategy, both routes share the same major limitation that MIP sites and membrane morphology are formed in the same step from the same building blocks, either monomer or polymers. Consequently, the limited accessibility of imprinted sites due to a random distribution inside and on the surface of the bulk polymer phase remains a major unsolved problem. 
In the third strategy, the MIMs are prepared using the surface imprinting method. With this technique, the available imprinted sites are mostly located on the membrane surface, thus facilitating fast recognition, especially for natural macromolecules. Besides, due to the high porosity and good mechanical properties of the support membrane, the resultant composite membrane exhibited a large surface area to volume ratio, excellent permeability, binding capability, and good stability. Several methods were developed to form imprinting sites on the surface [26]. One of the preferred methods to prepare such membranes is by surface grafting of functional layers to the base membrane's pore surface. It can be accomplished by an intrinsic initiation of photosensitive groups introduced onto the surface membrane or by coated initiation via a hydrogen-abstracting photoinitiator that yields polymer starter radicals on the substrate [20]. This last option can be easily adapted to any type of membrane with the presence of $\mathrm{C}-\mathrm{H}$ bonds, e.g., a porous polypropylene (PP) membrane. Figure 4 illustrates an example of surface photo-grafting for the formation of molecularly imprinting sites.

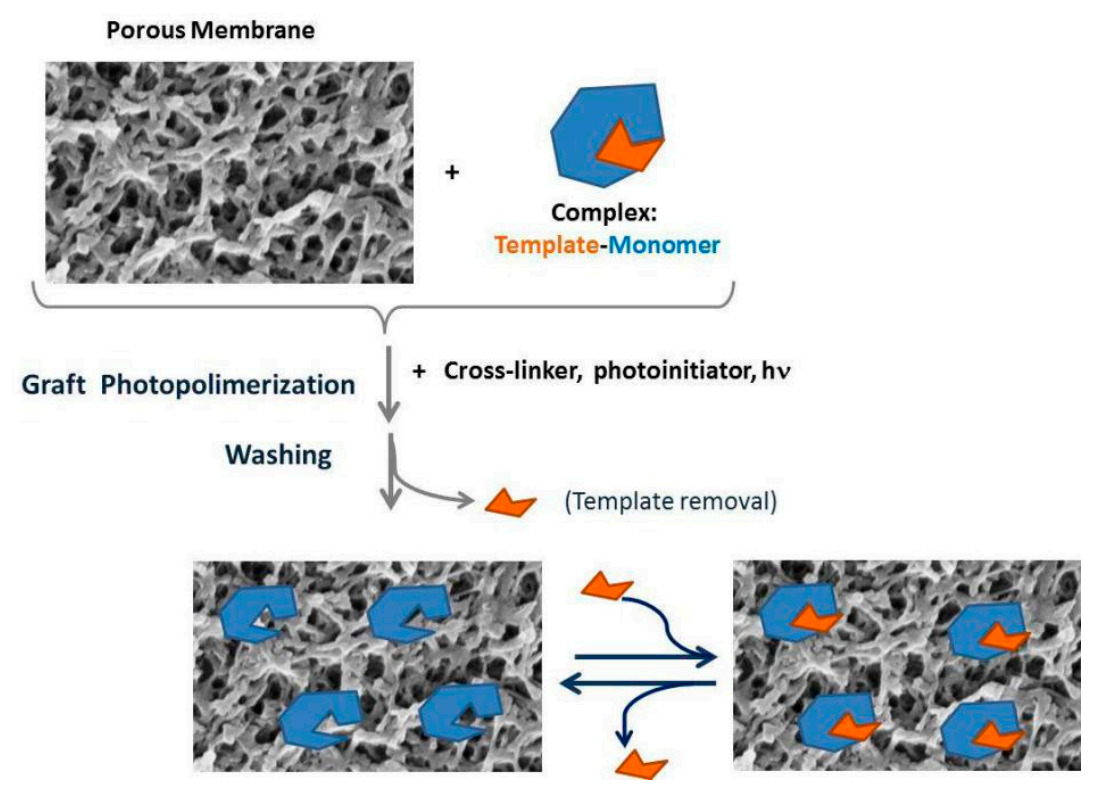

Figure 4. Scheme of surface photo-grafting for the formation of a molecularly imprinted sites in a membrane.

An example of illustration of the surface structure of MIMs obtained by this imprinting technique is given in Figure 5 [27]. As can be observed, a layer of polymer coated the surface of polyvinylidene fluoride (PVDF) membrane in NIM and MIM (Figure 5b,c, respectively). Besides, the images also showed that MIM (at the same magnification) was rougher than NIM, which was due to the coating of thin template layer on the top surface of PVDF membrane.
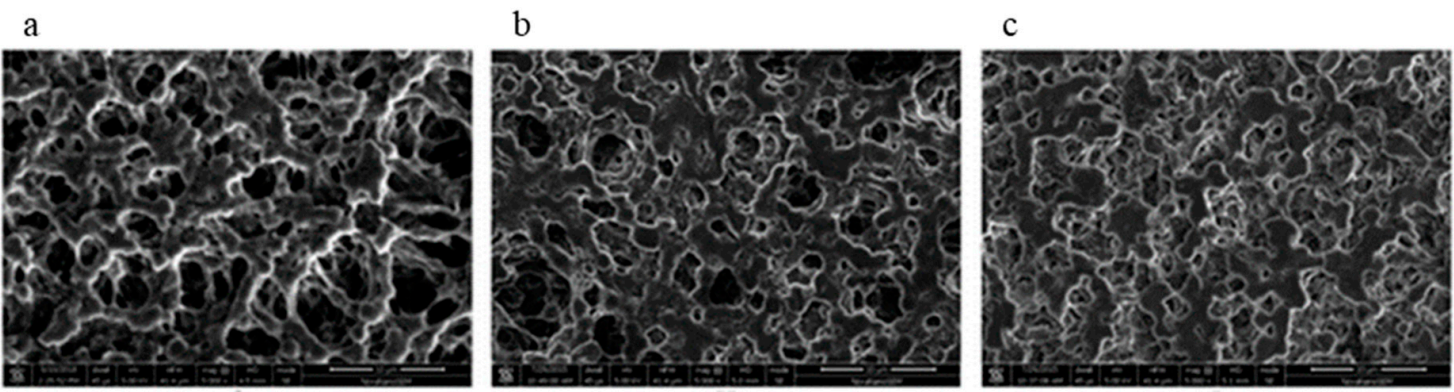

Figure 5. SEM photographs of (a) blank PVDF membrane, (b) NIM and (c) MIM prepared by grafting onto the membrane. Reproduced with permission from [27]. 
Also, other approaches such as surface deposition [26], emulsion polymerization [26], or even electrospinning [28] were used to create imprinting sites on the surface membrane. For instance, a MIP layer on the surface of electrospun micro/nanofibers, which acts as a support for the imprinted polymer, can be produced either in absence of specific interactions with the support, or via specific grafting approaches. A scheme of this approach can be depicted in Figure 6. In particular, the "grafting" approaches provide an effective way of changing the chemical and physical properties of the fibers and the resulting materials are potentially more robust over longer periods of time compared to blending. Besides, grafting of polymers from the surface of the fiber is preferred since the grafting densities can be tailored and hence more effective control over biointerfacial interactions can be achieved [28].

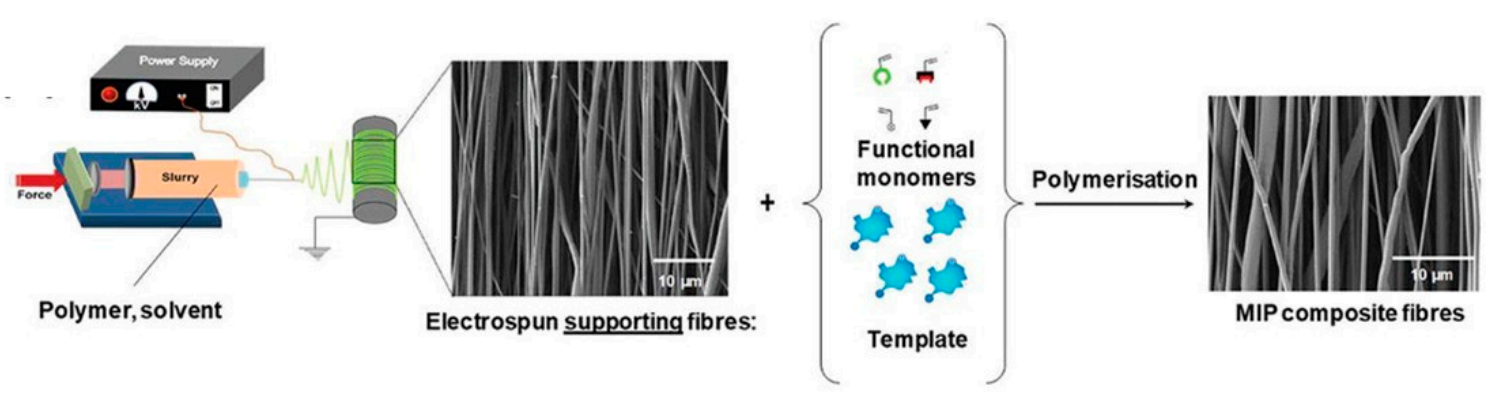

Figure 6. Schematic illustration of electrospinning set-up, production of fibers, and a MIP layer on the surface of fibrous membranes. In this example, a MIP layer is made onto the surface of electrospun supporting fibers. Reproduced with permission from [28].

To improve some physical properties of MIMs, in recent years, nanoparticles (NPs) were also added to the membranes in all above-mentioned strategies, particularly in the second and third ones [29]. The particular properties of these nanostructures relies on the type of NP as well as their features (size and shape), which will allow the use depending on the analytical needs. With the aim of obtaining composite membrane materials with enhanced flux, better anti-fouling properties, chemical stability and great perm-selectivity, NPs were incorporated into the membranes. As an example, it was found that MIMs modified by different inorganic nanocomposite, such as $\mathrm{SiO}_{2}$ [30] and $\mathrm{TiO}_{2}$ [31] demonstrated excellent rebinding ability and enhanced performance features. More examples of molecularly imprinted nanocomposite membranes and their application to sample preparation and separation processes will be given in the following sections.

\section{Use of MIMs in Sample Preparation}

Several MIMs were recently developed and applied for selective extraction and determination of pharmaceutical compounds, drugs, mycotoxins, residual pesticides, and persistent organic pollutants in biological, food, and environmental matrices. Different synthetic approaches were practiced, involving various polymerization techniques, and/or supporting substrates, to prepare MIM materials with different physical-chemical properties, selectivity, and analytical applicability. Other approach different to the development of MIMs by the above-mentioned imprinting techniques is that based on the introduction (enclosing) of a small amount of MIP particles ( $\leq 100 \mathrm{mg}$ ) into the lumen of the membrane. This combination protects the sorbent from with a physical contact with the sample matrix, while the analytes are allowed to diffuse across the membrane before adsorption onto the enclosed solid adsorbent. In this section, the most relevant contributions in the sample treatment field of MIMs as efficient and selective extraction devices will be briefly discussed, and an overview of the applications is summarized in Table 1. 
Table 1. Recent MIM-based sorbents for extraction purposes in pharmaceutical, clinical, food and environmental samples.

\begin{tabular}{|c|c|c|c|c|c|c|c|c|}
\hline Analyte(s) & $\begin{array}{l}\text { Template/Monomer/ } \\
\text { Crosslinker/Solvent }\end{array}$ & Substrate & Imprinting Technique & Matrix & $\begin{array}{l}\text { Determination } \\
\text { Technique }\end{array}$ & $\begin{array}{c}\text { Recovery } \\
(\%)\end{array}$ & $\begin{array}{c}\text { LOD } \\
\left(\mathrm{ng} \mathrm{mL} \mathrm{mL}^{-1}\right)\end{array}$ & Reference \\
\hline \multicolumn{9}{|c|}{ Pharmaceutical and clinical } \\
\hline 5-FU & 5-FU/MAA/EGDMA/MeOH:ACN & PET & Electrospinning & Urine & HPLC-UV & $>93$ & 0.023 & [32] \\
\hline $\mathrm{TE}$ & $\mathrm{TE} / \mathrm{AAM} / \mathrm{EGDMA} / \mathrm{MeOH}$ & Organic nylon PVDF; PP & Surface grafting & Serum & UV & $>70.8$ & - & [27] \\
\hline $\mathrm{VCM}$ & VCM/AAM/EGDMA/MeOH & Organic nylon; PVDF; PP & Surface grafting & Serum & UV & $>78$ & - & [33] \\
\hline L-Tys & L-Tys $/ \gamma$-MPS/ACN & PSf & Surface grafting & Plasma & LC/MS/MS & $>80$ & $0.1 \mathrm{nmol} \mathrm{L}^{-1}$ & {$[34]$} \\
\hline CLE & & & & Urine & & & & \\
\hline $\begin{array}{l}\text { MTX } \\
\text { CPFX }\end{array}$ & $\begin{array}{c}\text { CLE or MTX or CPFX or } \\
\text { CPF/MAA/EGDMA/CHCl } 3: \mathrm{MeOH}\end{array}$ & PVDF & Surface grafting & $\begin{array}{l}\text { Blood } \\
\text { Milk }\end{array}$ & ESI-MS & $>91 \%$ & 0.02 (CLE) & [35] \\
\hline CPF & & & & Soil & & & & \\
\hline $\begin{array}{l}\text { Cocaine } \\
\text { COC }\end{array}$ & Cocaine/MAA/EGDMA/ $\mathrm{H}_{2} \mathrm{O}$ & Cellulose & Surface grafting & Oral fluid & PSI-MS & $>100.5$ & 0.27 & [36] \\
\hline $\begin{array}{l}\text { BZE } \\
\text { CE } \\
\text { EME }\end{array}$ & COC/EGDMA/DVB/ACN:TOL & $\mathrm{PP}$ & $\begin{array}{l}\text { In situ polymerization } \\
\text { (MIP particles enclosed in } \\
\text { membrane) }\end{array}$ & Urine & HPLC-MS/MS & $>97$ & $0.05-0.5$ & [37] \\
\hline $\begin{array}{l}\text { COC } \\
\text { BZE } \\
\text { CE } \\
\text { EME }\end{array}$ & COC/EGDMA/DVB/ACN:TOL & PP & $\begin{array}{l}\text { In situ polymerization } \\
\text { (MIP particles enclosed in } \\
\text { membrane) }\end{array}$ & Plasma & HPLC-MS/MS & $>96$ & $0.06-0.87$ & [38] \\
\hline $\begin{array}{l}\text { Cannabinoids } \\
\text { (JWH007; JWH015; } \\
\text { JWH098) }\end{array}$ & JWH105/EGDMA/DVB/ACN:TOL & PP & $\begin{array}{l}\text { In situ polymerization } \\
\text { (MIP particles enclosed in } \\
\text { membrane) }\end{array}$ & Urine & HPLC-MS/MS & $>86$ & $0.032-0.75$ & [39] \\
\hline $\begin{array}{l}\text { Synthetic } \\
\text { cathinones }\end{array}$ & Ethylone/EGDMA/DVB/ACN:TOL & $\mathrm{PP}$ & $\begin{array}{l}\text { In situ polymerization } \\
\text { (MIP particles enclosed in } \\
\text { membrane) }\end{array}$ & Urine & HPLC-MS/MS & $>92$ & $0.14-1.02$ & [40] \\
\hline \multicolumn{9}{|c|}{ 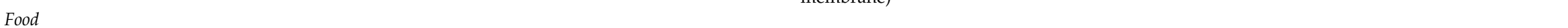 } \\
\hline CIT & $\begin{array}{l}\text { 1-naphthol/Methacryloyl } \\
\text { chloride/DVB/Ace: } \mathrm{H}_{2} \mathrm{O}\end{array}$ & PES & Phase inversion & Rice & HPLC-FD & $>90$ & $0.5 \mathrm{ng} \mathrm{g}^{-1}$ & [41] \\
\hline Acesulfame & Acesulfame/TEPAM/ACN & Nylon 6 & Electrospinning & Beverages & HPLC-UV & $>80$ & 0.6 & [42] \\
\hline Melamine & $\begin{array}{c}\text { Melamine/MAA/EGDMA/ } \\
\text { ACN: } \mathrm{H}_{2} \mathrm{O}\end{array}$ & CA & Surface grafting & Milk & HPLC-UV & $>89$ & 7 & [43] \\
\hline $\begin{array}{l}\text { 2,4-D } \\
\text { Diuron }\end{array}$ & $\begin{array}{c}\text { 2,4,5-TD or monuron/MAA/ } \\
\text { EGDMA/MeOH }\end{array}$ & $\mathrm{CM}$ & Surface grafting & Fresh fruit & PSI-MS & $>92$ & $0.17-0.6$ & [44] \\
\hline $\begin{array}{l}\text { Aflatoxins } \\
\text { (AFB1; AFB2; } \\
\text { AFG1; AFG2) } \\
\text { Environmental }\end{array}$ & DMC/MAA/DVB/ACN:TOL & PP & $\begin{array}{l}\text { In situ polymerization } \\
\text { (MIP particles enclosed in } \\
\text { membrane) }\end{array}$ & Fish feed & UHPLC-MS-MS & $>80$ & $\begin{array}{l}0.42-1.2 \mu \mathrm{g} \\
\mathrm{Kg}^{-1}\end{array}$ & [45] \\
\hline SA & SA/CS/DMSO & CA & Phase inversion & Water & FD & - & 24000 & [46] \\
\hline $\begin{array}{l}\text { SMX } \\
\text { SMM } \\
\text { SDZ }\end{array}$ & SMX/APTES/TEOS/ACN & Agarose & $\begin{array}{l}\text { In situ polymerization } \\
\text { (encapsulated) }\end{array}$ & Water & HPLC-DAD & $80-96$ & $0.06-0.17$ & [47] \\
\hline
\end{tabular}


Table 1. Cont.

\begin{tabular}{|c|c|c|c|c|c|c|c|c|}
\hline Analyte(s) & $\begin{array}{l}\text { Template/Monomer/ } \\
\text { Crosslinker/Solvent }\end{array}$ & Substrate & Imprinting Technique & Matrix & $\begin{array}{l}\text { Determination } \\
\text { Technique }\end{array}$ & $\begin{array}{l}\text { Recovery } \\
(\%)\end{array}$ & $\begin{array}{c}\text { LOD } \\
\left(\mathrm{ng} \mathrm{mL} \mathrm{mL}^{-1}\right)\end{array}$ & Reference \\
\hline $\begin{array}{l}\text { Diclofenac } \\
\text { Metoprolol } \\
\text { VCM }\end{array}$ & $\begin{array}{c}\text { Diclofenac or metoprolol or } \\
\text { VCM/NIPAm, AAc, TBAm /Bis } \\
/ \mathrm{H}_{2} \mathrm{O}\end{array}$ & PVDF & Surface grafting & Water & HPLC-UV & $50.1-100$ & $3.7-15$ & [48] \\
\hline PAHs & $\mathrm{B}[\mathrm{k}] \mathrm{F}+$ Indeno/p-vinylbenzene/EDGMA/DMF & PP & $\begin{array}{l}\text { In situ polymerization } \\
\text { (MIP particles enclosed in } \\
\text { membrane) }\end{array}$ & Wastewater & GC-TOF/MS & 63-96 & $0.01-0.45$ & [49] \\
\hline
\end{tabular}

2,4-D: 2,4-dichloropehnoxyacetic acid; 2,4,5-T: 2,4,5-trichlorophenoxyacetic acid; 5-FU: 5-fluorouracil; AAc: acrylic acid; ACN: acetonitrile; Ace: acetone; Bis: N,N'-methylenebisacrylamide; B[k]F: benzo[k]fluoranthene; BZE: benzoylecgonine; CA: cellulose acetate; CE: cocaethylene; CIT: citrinin; CLE: clenbuterol; CM: Cellulose membrane; COC: Cocaine; CPF: chlorpyrifos; CPFX: ciprofloxacin; CS: chitosan; DMC: 5,7-dimethoxycoumarin; DMF: dimethylformamide; DMSO: dimethyl sulfoxide; DVB: divinylbenzene; EGDMA: ethylene glycol dimethacrylate; EME: ecgonine methyl ester; ESI-MS: electrospray ionization-mass spectrometry; FD: fluorescence detection; GC-TOF/MS: gas chromatography-time of flight mass spectrometer; L-Tys: L-tyrosine; MAA: methacrylic acid; MDPV: 3,4-methylenedioxypyrovalerone; MeOH: methanol; $\gamma$-MPS: 3-(trimethoxysilyl)propyl methacrylate; MTX: methotrexate; NIPAm: N-isopropylacrylamide; PAH: polycyclic aromatic hydrocarbon; PES: Polyethersulfone; PET: polyethylene terephthalate; PSf: polysulfone; PP: polypropylene; PSI-MS: paper spray ionization-mass spectrometry; PVDF: polyvinylidene fluoride; SA: salicylic acid; SDZ: sulfadiazine; SMM: sulfamonomethoxine; SMX: sulfamethoxazole; TE: teicoplanin; TBAm: N-tert-butylacrylamide; TEPAM: 3-triethoxysilyl propylamide; TOL: toluene; VCM: vancomycin. 


\subsection{Pharmaceutical and Clinical Applications}

Beigzadeh et al. [32] made a MIM as SPE support for the selective extraction of 5-fluorouracil (anti-cancer chemotherapy drug) from urine samples prior to HPLC-UV determination. For this purpose, the authors fabricated the MIM via the encapsulation of MIP nanoparticles in electrospinning polyethylene terephthalate (PET) nanofibers. Under optimized conditions, the developed method showed high recoveries (93-95\%) in urine samples and low LODs $\left(0.023 \mu \mathrm{g} \mathrm{L}^{-1}\right)$. Besides, the selectivity of MIM was satisfactory since the presence of other cytotoxic drugs (ifosfamide and cyclophosphamide) in the solution had no effect on the recovery values of target analyte.

Yao et al. [27] reported a MIM for teicoplanin (TE), a glycopeptide antibiotic, in biological samples prior UV determination. For this purpose, several supporting materials (organic nylon microporous, polyvinylidene fluoride (PVDF) and polypropylene (PP) membranes) were activated by soaking in a solution of azobisisobutyronitrile (AIBN) in acetonitrile. Then, the activated membranes were immersed in the molecular imprinting solution (TE and the functional monomer acrylamide) and subjected to thermal polymerization. The best performance was shown by PVDF MIM, with maximum loading capacity of $85 \mu \mathrm{g} \mathrm{cm}^{-2}$. The selected MIM showed satisfactory recoveries $(>70.6 \%)$ both in phosphate buffer solution $\left(0.1 \mathrm{~mol} \mathrm{~L}^{-1} \mathrm{pH} 2.50\right)$ as well as in a fetal bovine serum matrix (after protein removal). Another example of surface imprinting technique was proposed by the same authors [33] for the extraction of vancomycin (VCM) in serum samples followed its UV determination. The resulting MIM showed a good adsorption capacity $\left(23.8 \mu \mathrm{g} \mathrm{cm}^{-2}\right)$ and adequate selective adsorption capability (recovery of VCM in a solution containing teicoplanin as interferent compound gave values of $116 \%$ ). Besides, the developed MIM was satisfactorily used (recoveries values $>78 \%$ ) to the direct determination of VCM in serum whether the proteins were in the system or not.

Another interesting example of surface imprinting technique was developed by Moein et al. [34]. Therein, the authors described the modification of a polysulfone (PSf) membrane using an in situ MIP sol-gel method for the selective extraction and screening of L-tyrosine (as a lung cancer biomarker) in plasma samples. The modified molecularly imprinted sol-gel PSf membrane was placed in a homemade plastic tube and coupled on-line with LC/MS/MS for the selective extraction of this compound. The analytical features of the optimized method were as follows: satisfactory recoveries (80-85\%), excellent reusability of sorbent (at least 50 times), and low LOD $\left(0.1 \mathrm{nmol} \mathrm{L}^{-1}\right)$.

A remarkable application of the combination of MIM with ambient electrospray ionization for direct sample analyses was reported by Li et al. [35]. The combination of MIM and ESI-MS provides a chemically selective surface that avoids the limitations of paper spray ionization (PSI) (such as low sensitivity and ionization suppression) when complex samples are analyzed. Thus, a PVDF membrane was previously activated by soaking in a solution containing $10 \%$ acrylic acid and $1 \%$ potassium peroxydisulfate at $70{ }^{\circ} \mathrm{C}$ for $12 \mathrm{~h}$. Next, the activated membrane was immerged in the prepolymer solution, and subsequently thermally polymerized. Several MIMs using different templates (clenbuterol hydrochloride (CLE), methotrexate (MTX), chlorpyrifos (CPF) and ciprofloxacin (CPFX)) were prepared and applied to enrich these target molecules in complex matrices before their analysis by ESI-MS (see scheme in Figure 7). For example, the LOQ achieved for CLE was $0.1 \mathrm{ng} \mathrm{mL}^{-1}$, which let to quantify this analyte in urine samples. Besides, this study also demonstrated the use of MIM-ESI-MS in different application fields, where low LOQs were achieved $\left(0.5 \mathrm{ng} \mathrm{mL}^{-1}, 1 \mathrm{ng} \mathrm{mL}^{-1}\right.$, and $1 \mathrm{ng} \mathrm{mL}^{-1}$ for MTX in blood, CPF in soil, and CPFX in milk, respectively). Additionally, MIM spray ionization is a relatively fast method to perform, since the MIM is produced in less than $24 \mathrm{~h}$ and the PSI analysis can be done in seconds. 


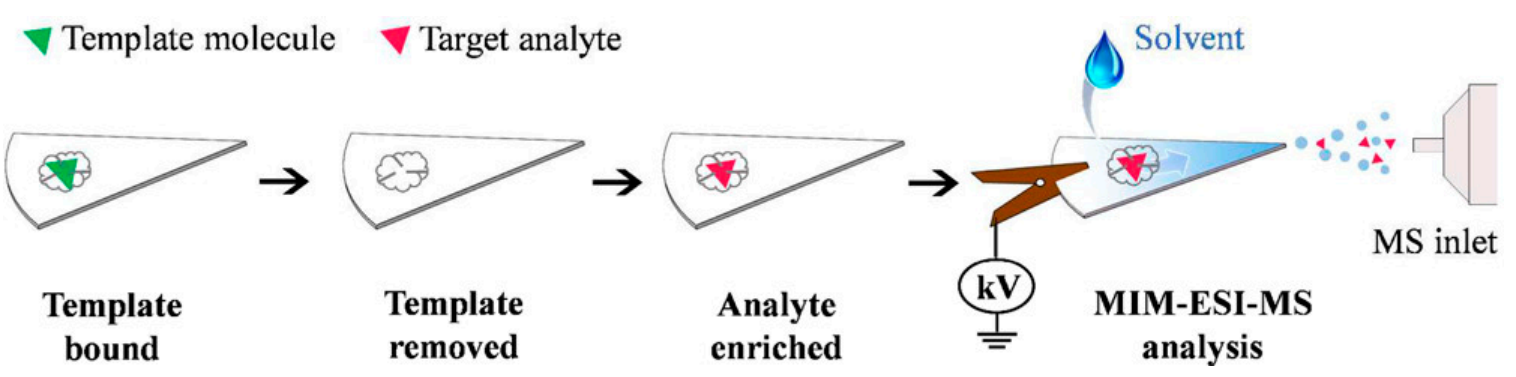

Figure 7. Workflow and analyte ionization in MIM-ESI. Reproduced with permission from [35].

Inspired by this last work, Tavares et al. [36] developed a MIM, which was used in a paper spray ionization (PSI)-MS source for the analysis of cocaine in oral fluid samples. In this study, cellulose membrane (prior activated with benzophenone) was submerged in pre-polymerization solution followed UV polymerization. The developed MIM gave a LOD of $0.27 \mathrm{ng} \mathrm{mL}^{-1}$ and recoveries ranged between $100.5 \%$ and $105.3 \%$. Other benefits of the method were: no need for sample preparation, low solvent consumption and fast analysis $(<30 \mathrm{~s})$.

As we mentioned above, other group of micro-SPE procedures using MIPs and membranes imply that the adsorbent (MIP) is enclosed inside the membrane. Thus, Sánchez-González and co-workers [37-40] developed several MIP- $\mu$-SPE devices for different drugs (cocaine and cannabinoids) in urine or plasma samples. As shown in Figure 8, MIP particles were placed into the PP membrane using a cone-shape design with only one seal on the upper end. Then, the MIP- $\mu$-SPE device is introduced into the sample flask, followed by shaking and elution assisted by ultrasounds. This configuration avoids heat-sealing damage, and hence loss of MIP particles, since the heat-sealing in these devices is not in contact with eluting solvents. Besides, the capacity of the orbital-horizontal shaker allowed the simultaneous performance of several MIP- $\mu$-SPE units (at least 20), which undoubtedly increases the throughput of the method compared with microextraction by packed sorbent (MEPS) and on-line SPE approaches. As an example, the proposed system was applied for extraction of synthetic cannabinoids in urine followed by HPLC-MS analysis. Satisfactory recovery values $(83-100 \%)$, good reusability of sorbent (at least 27 times), and low LODs $\left(0.032-0.75 \mathrm{ng} \mathrm{mL}^{-1}\right)$ were achieved.

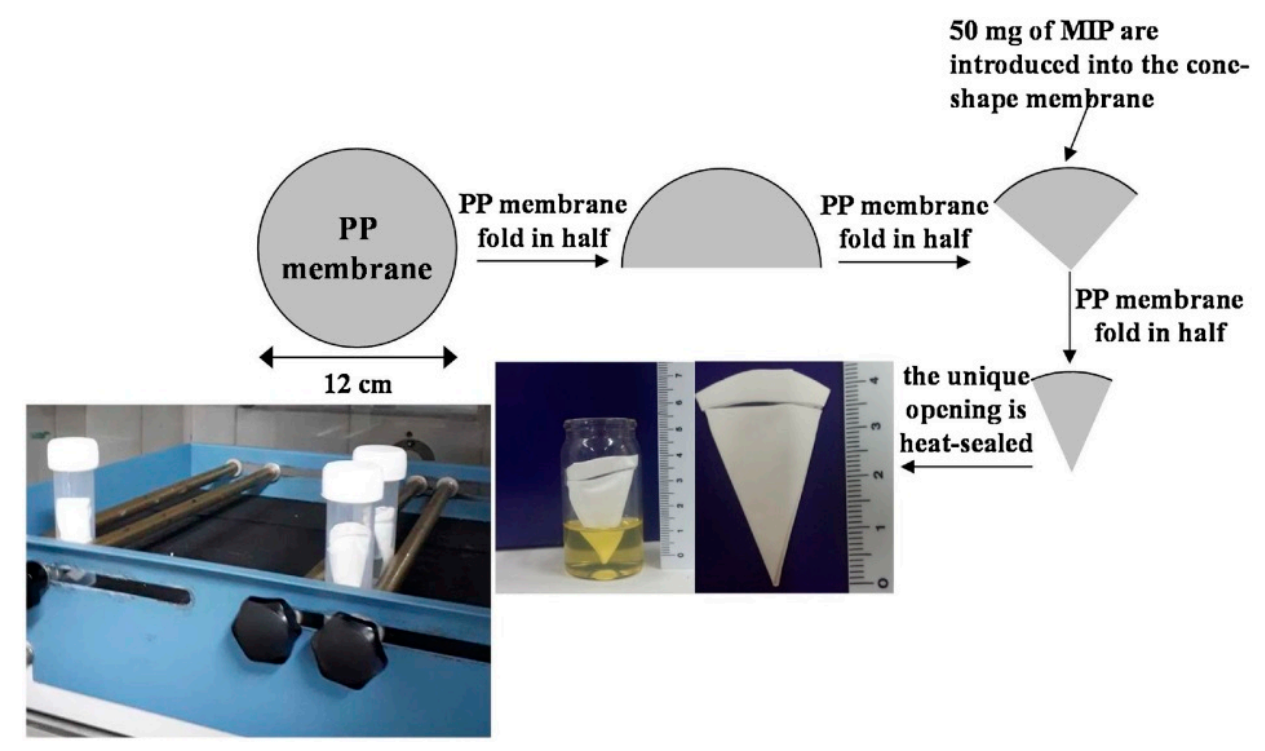

Figure 8. Scheme of preparation of MIP- $\mu$-SPE device. The sealed MIP- $\mu$-SPE device was conditioned, placed into the buffered sample, shaken, and properly eluted using ultrasonics. Reproduced with permission [39]. 


\subsection{Food Applications}

MIMs have been used for determination of mycotoxins in foods, such as citrinin (CIT), a metabolite produced by several fungal species of Aspergillus [41]. The authors developed MIMs for CIT with 1-naphthol as mimic template, divinylbenzene as crosslinker, and naphthol methacrylate hybridized into polyethersulfone scaffold by phase inversion process. The resulting MIM was used as SPE phase for the extraction and pre-concentration of the mycotoxin in rice samples prior to HPLC with fluorescence detection. Under optimized conditions, the developed method showed high recoveries (89.7-94.2\%), satisfactory precision values (RSD $<6.0 \%)$, and low LOD $\left(0.5 \mathrm{ng} \mathrm{g}^{-1}\right)$.

The monitoring and control of food additives is a critical issue in the food industry to guarantee food quality and promote food safety. Thus, Moein et al. [42] developed an electro spun molecularly imprinted nanomembrane for selective extraction and determination of acesulfame in beverage samples and on-line connected to HPLC system. Nylon 6 was used as a polymeric backbone to support the MIP precursor in the sol-gel process, and it was used to facilitate the electrospinning procedure. The MIM device gave an imprinting factor (which is determined by comparing the amount of target analyte or structural analog bound/retained by the MIM and the NIM) of 4.25 and showed a good selectivity for the target molecule compared to other sweeteners or food additives like saccharine, aspartame, and caffeine. The sorbent also provided a satisfactory reusability (at least for 35 re-uses without a significant change in extraction recovery). Other quality analytical parameters of the method included quantitative extraction recoveries for beverage samples (80-85\%), and low LOD $\left(0.6 \mathrm{ng} \mathrm{mL}^{-1}\right)$.

Other interesting application was reported by Akbari-Adergani et al. [43], who developed a MIM for the selective micro-extraction of melamine from milk samples, which was subsequently determined by HPLC. For this purpose, MIPs were photografted into the circular hydrophilic CA membrane by placing it into the pre-polymerization solution (see Figure 9). The resulting MIM showed a great selectivity compared to NIM, increasing the recoveries from $22-23 \%$ to $91-93 \%$. Besides, the developed method provided low LOD $\left(0.007 \mu \mathrm{g} \mathrm{mL}^{-1}\right)$ and satisfactory recovery values $(88.7-94.8 \%)$ in dry milk samples.

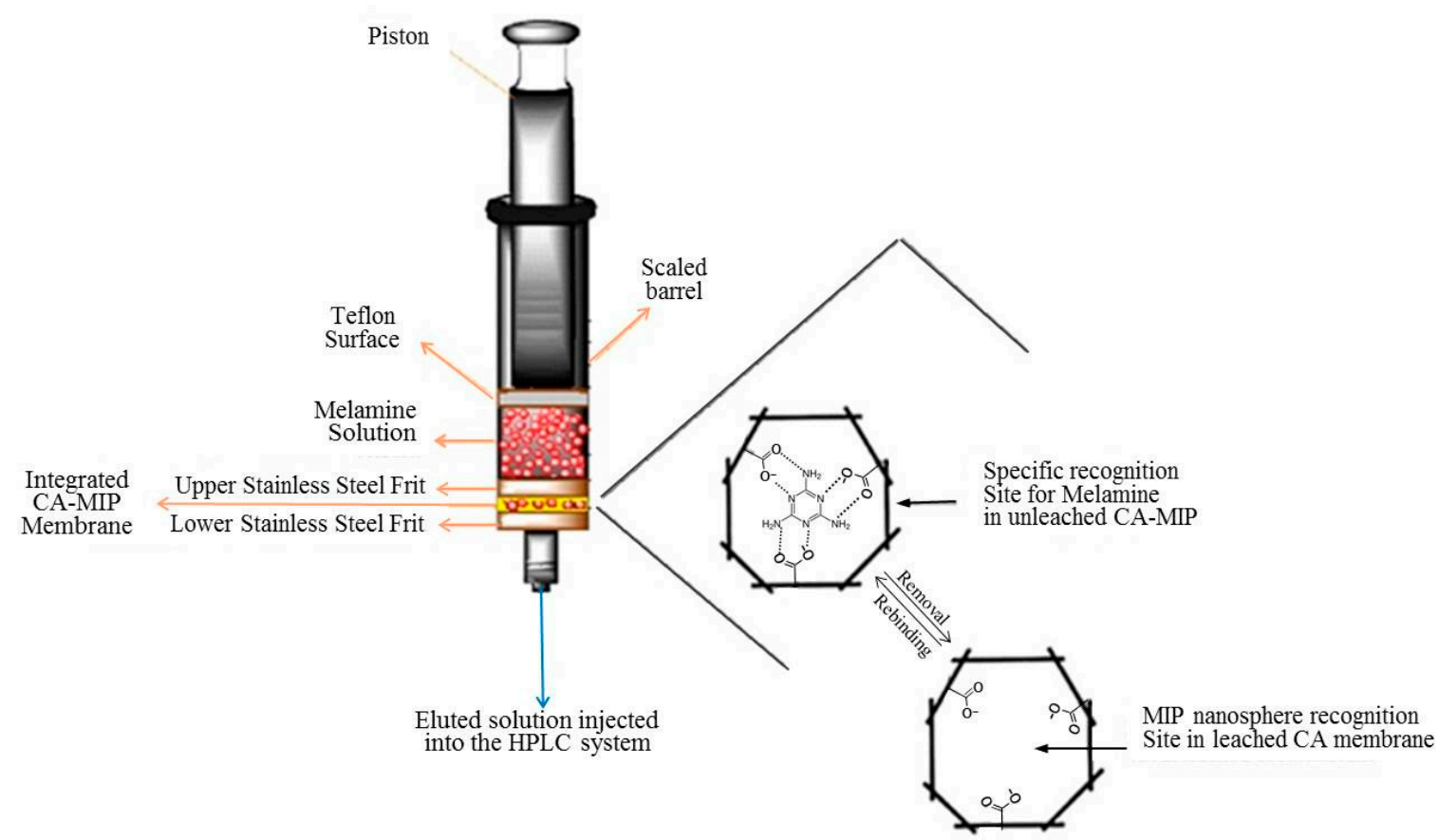

Figure 9. Schematic representation of recognition sites and extraction of melamine by photografted polymers in CA membrane network. Reproduced with permission from [43]. 
Also, the combination of MIM with PSI-MS was applied to the selective extraction and determination of herbicides such as diuron and 2,4-dichlorophenoxy acetic acid in foodstuffs [44]. Thus, MIP was synthesized onto an activated cellulose membrane. In this case, monuron and 2,4,5- trichlorophenoxyacetic acid were used as template molecules instead of the target analytes. The resulting MIP membrane spray showed signal intensities of analytes that were much higher than those obtained by non-imprinted polymers (NIP or NIM). The real applicability of the developed MIMs was demonstrated by separation/extraction of these herbicides from food samples (with recoveries from $92.5 \%$ and $116.9 \%$ ) and with LODs less than $0.60 \mu \mathrm{g} \mathrm{L}^{-1}$.

Also, the use of MIPs enclosed in membranes was applied to food safety purposes [45]. The authors used single cone-shape PP devices containing MIP particles as a $\mu$-SPE system for the selective extraction of aflatoxins in fish feed, which were determined by HPLC-MS. The analytical features of the optimized method were as follows: satisfactory recoveries (80-100\%), good reusability and low LODs $\left(0.42-1.2 \mu \mathrm{g} \mathrm{kg}^{-1}\right)$. These LOD values were quite lower than those established by European Commission guidelines for aflatoxins in animal feeds.

\subsection{Environmental Applications}

Meng et al. [46] developed a fluorescent MIM (FMIM) for salicylic acid (SA) using the phase inversion technique, with SA as template molecule, chitosan as functional polymer. As luminescent material, complexes of Europium with 2-thenoyltrifluoroacetone (Eu(TTA) $)_{3}$ phen) incorporated into the cavities of a polyamidoamine (PAMAM) dendrimer (Eu(TTA) $)_{3}$ phen/PAMAM) were used. Figure 10 shows the preparation process of FMIM and its fluorescence mechanism.
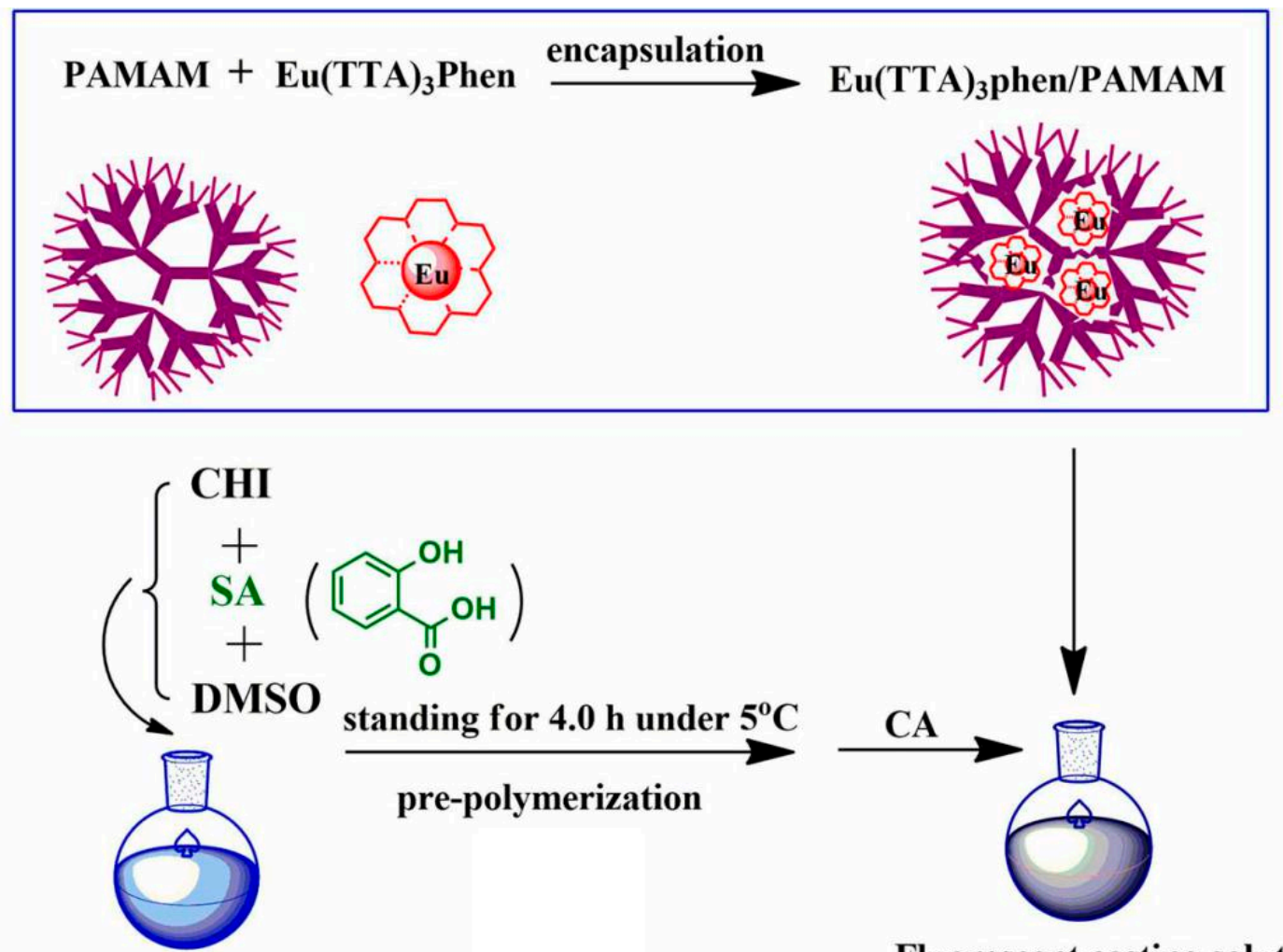

Fluorescent casting solution

Figure 10. Scheme of formation of FMIM and its fluorescent mechanism. Reproduced with permission from [46].

The FMIM prepared with $2.0 \% \mathrm{Eu}(\mathrm{TTA})_{3}$ phen/PAMAM in the cast membrane fluid was the optimal fluorescent imprinted membrane for selective detection of SA, which displayed a relatively 
wider linear range $\left(0-100 \mathrm{mg} \mathrm{L}^{-1}\right)$, acceptable LOD $\left(24 \mathrm{mg} \mathrm{L}^{-1}\right)$, and satisfactory recycling performance (at least four times). Besides, the FMIM had acceptable fluorescent selectivity toward structural analogues of SA, and it was successfully used for selective detection and separation of SA in water.

Rozaini et al. [47] dispersed molecularly imprinted silica gel particles in an agarose polymer matrix to form a mixed matrix membrane for the separation and preconcentration of sulfonamides in environmental water samples, and their subsequence determination by HPLC. The developed method offered the following benefits: (i) simple and fast sample preparation and HPLC analysis ( $<15 \mathrm{~min})$; (ii) low organic solvent requirement $(250 \mu \mathrm{L})$ and low sorbent consumption ( $15 \mathrm{mg}$ per membrane), and (iii) cost-effective. In addition, the proposed protocol provided good recoveries (80-96\% with RSD values $<10 \%$ ), high selectivity (selectivity factors of the MIM were between 1.5 and 5.2) and sensitivity (LOD lower than $0.17 \mu \mathrm{g} \mathrm{L}^{-1}$ ) allowing the quantification of these compounds at levels below the maximum residue limits established by regulatory agencies.

Altintas et al. [48] developed nanostructured MIMs using PVDF membranes previously subjected to plasma treatment for surface modification. This treatment allowed the addition of functional groups to the membranes prior to incorporating high capacity and affinity MIPs both by adsorption and covalent immobilization. In this case, acrylic acid was used as the monomer during the plasma deposition process and a high density of carboxylic groups were obtained at the surface of the membranes (see Figure 11). Then, individual MIP solutions (containing as template diclofenac-, metoprolol- or vancomycin, respectively) were applied and the resulting nanoMIPs were immobilized. The resulting MIMs were used as SPE phases for the extraction of these analytes in water samples prior HPLC determination. The optimized method gave satisfactory LODs $\left(3.7-15 \mathrm{ng} \mathrm{mL}^{-1}\right)$ and acceptable recoveries (nearly $100 \%$ for metoprolol and diclofenac, and ca. $50 \%$ for vancomycin). Moreover, a pilot scale test was made, and high volumes (up to $5 \mathrm{~L}$ ) were successfully applied, thus indicating the high potential of water purification using MIMs.

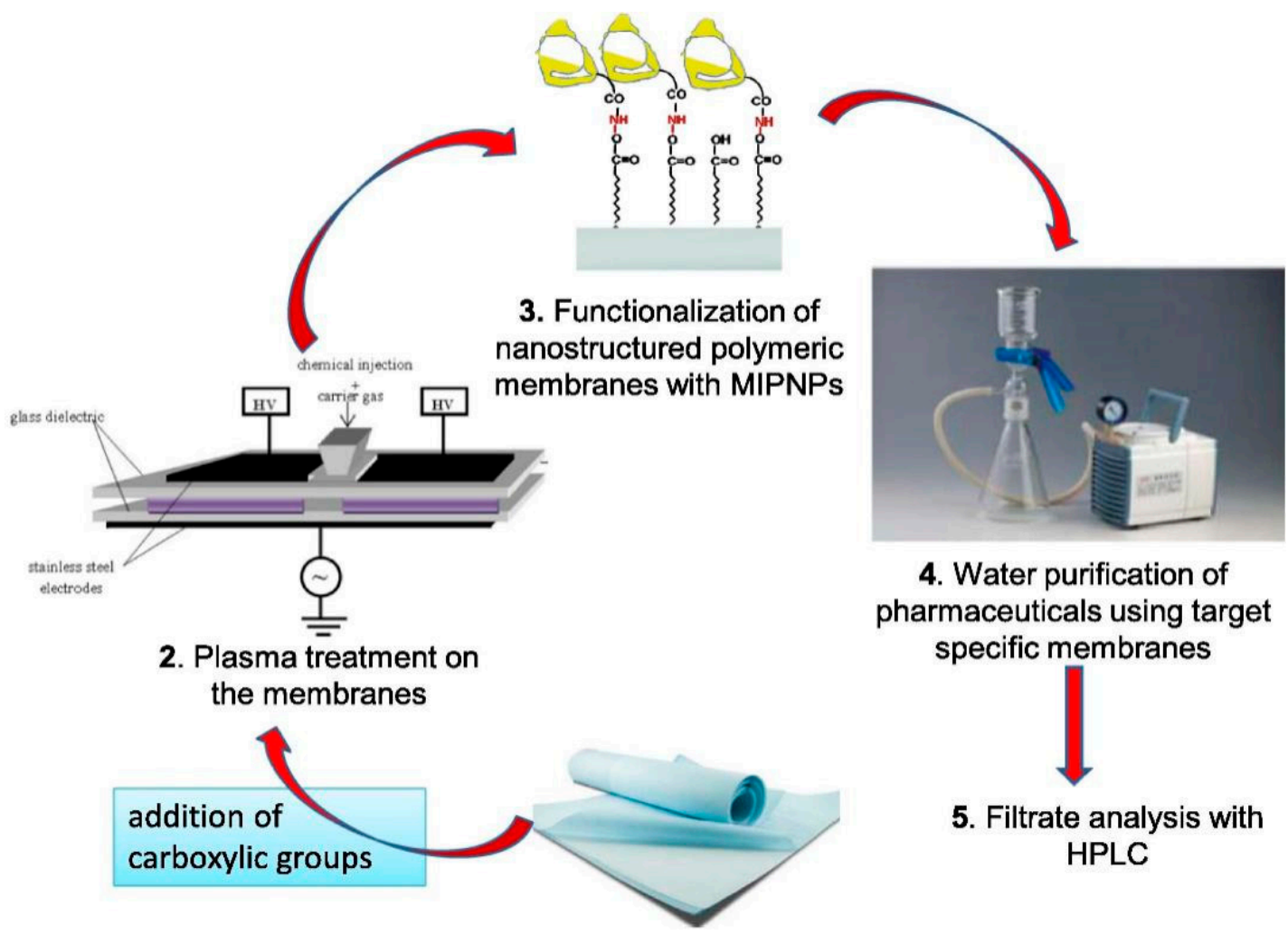

1. PVDF membranes

Figure 11. Preparation of functionalized nanostructured MIMs and their application for water purification of pharmaceuticals. Reproduced with permission from [48]. 
Also, the combination of membrane assisted solvent extraction and a MIP adsorbent (MASE-MIP technique) into a single step format was described for extraction of polycyclic aromatic hydrocarbons (PAHs) in wastewater followed by their determination by GC-TOF/MS [49]. As shown in Figure 12, the membrane extraction cell consisted of a $20 \mathrm{~mL}$ headspace vial filled with deionized water spiked with PAHs. The membrane bag was attached to a metal funnel and fixed with a PTFE ring. The membrane bag was filled with $80 \mathrm{mg}$ of the MIP particles and $1 \mathrm{~mL}$ of an organic acceptor phase. Under optimized conditions, the method provided good extraction efficiencies (62.8 to 96.8\%), acceptable reproducibility values $\left(\mathrm{RSD}=0.6-24.9 \%\right.$ ) and LODs ranged from $0.01-0.45 \mathrm{ng} \mathrm{mL}^{-1}$.

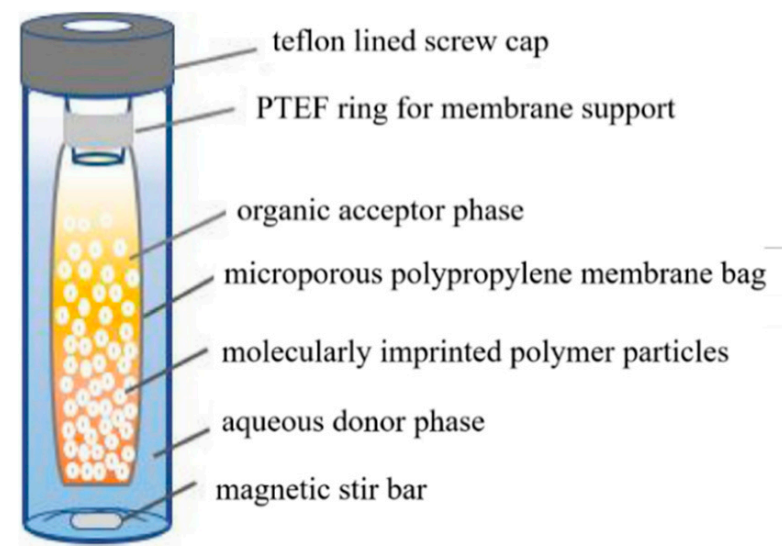

Figure 12. Experimental set-up of the MASE-MIP technique for the analysis of PAHs in wastewater. Reproduced with permission from [49].

\section{Use of MIMs in Separation Processes}

Also, MIMs are commonly used in selective molecular separation processes, including reverse osmosis, nanofiltration, pervaporation, and membrane adsorption. Indeed, these membranes have been employed in purification of active pharmaceutical ingredients, enantiomeric separation, extraction of toxic compounds such as metal ions, herbicides, PAHs, and dyes in environmental samples. However, most of these works were focused on characterization studies of MIMs with scarce emphasis in the application to real samples. Tables 2 and 3 list several selected examples of the use of MIMs in the separation of compounds with pharmaceutical, food or environmental interest. Next, the most relevant contributions in this field will be briefly discussed.

\subsection{Pharmaceutical and Food Applications}

In recent years, important efforts have been done for the purification of many drug components from neat solutions, raw materials, or natural sources by using MIMs [23,50-52]. For instance, Székely et al. [23] prepared an aminopyrimidine (2AP) molecularly imprinted nanofiltration membrane via phase inversion. The authors used polybenzimidazole (PBI) as a functional polymer for the molecular imprinting. The resulting MIM exhibited excellent chemical and solvent stability and it acted as shape specific adsorbent and size exclusion membrane (Figure 13).

In another example, Ghasemi et al. [52] developed a PSf membrane with specific nanocavities for the selective separation and enrichment of paclitaxel, an anticancer drug widely used in the treatment of different cancers, from a standard solution and from a natural source, yew tree extract. By using this MIM, $48 \%$ of the initial paclitaxel in the crude yew tree was separated by the membrane, which demonstrated its applicability in the purification of paclitaxel in an easier way than the preparative HPLC columns.

Cui et al. [51] prepared bio-inspired MIMs for the purification of artemisinin (Ars), an antiparasitic drug mainly extracted from plants. The authors, inspired from the highly bioadhesive performance of mussel protein, bound bio-adhesive and homodisperse polydopamine (pDA) layers on membrane 
surfaces (in particular, PVDF membranes) to form a versatile platform for further modification procedure. Then, Ars was used as template, AM as functional monomer and EGDMA as cross-linker to prepare the imprinted membranes via atom transfer radical polymerization (ATRP) technique. The resulting MIM showed a large adsorption capacity $\left(158.85 \mathrm{mg} \mathrm{g}^{-1}\right)$ and presented better perm-selectivity and reusability performance than NIMs. The same authors of this study also developed several pDA-based imprinted nanomaterials or platforms, such as $\mathrm{pDA} @ \mathrm{SiO}_{2}$ nanoparticles [53] and pDA@RC [54] for purification/separation of $\beta$-blockers, pDA@GO [55] and pDA@ $\mathrm{TiO}_{2}$ microspheres [56] for NSAIDs, and pDA@ $\mathrm{Al}_{2} \mathrm{O}_{3}$ [57] for isolation of antibiotics. For example, ibuprofen-imprinted nanocomposite membranes were prepared by the integration of $\mathrm{pDA} @ \mathrm{TiO}_{2}$ functional microspheres and porous PVDF membranes. By using ibuprofen as the template molecule, the final membranes were synthesized by developing a sol-gel imprinting technique (see Figure 14). The as-prepared membranes revealed a satisfactory adsorption capacity toward ibuprofen $\left(42.14 \mathrm{mg} \mathrm{g}^{-1}\right)$ and regenerability. Additionally, the as-synthesized imprinting membrane exhibited an excellent perm-selectivity toward ibuprofen with a separation factor of 4.46 .
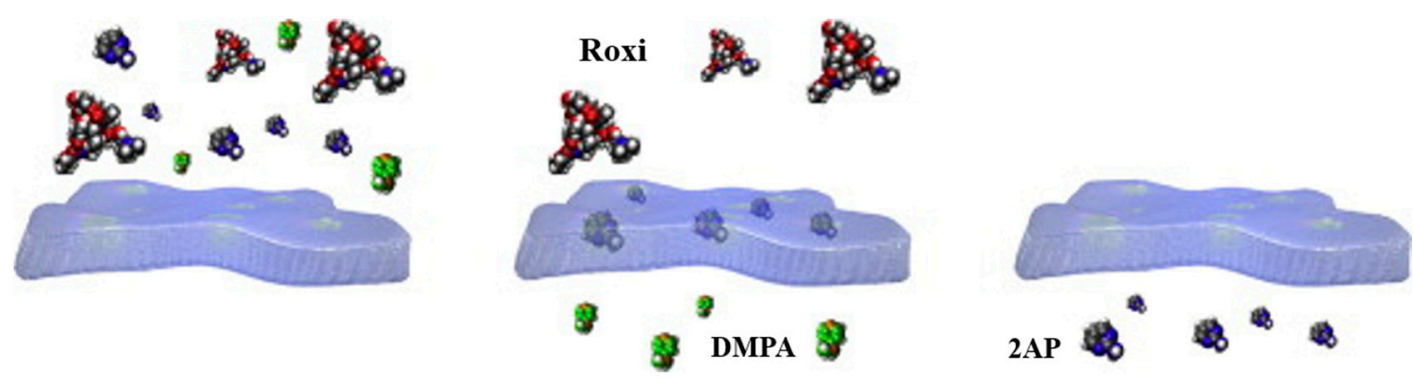

Figure 13. Separation process in nanofiltration MIM: (i) loading the ternary system of roxithromycin (Roxi), 2AP and 4-dimethylaminopyridine (DMAP); (ii) three way separation via retention of Roxi, adsorption of 2AP and permeation of DMAP; (iii) recovery of 2-AP and regeneration of the membrane. Reproduced with permission from [23].

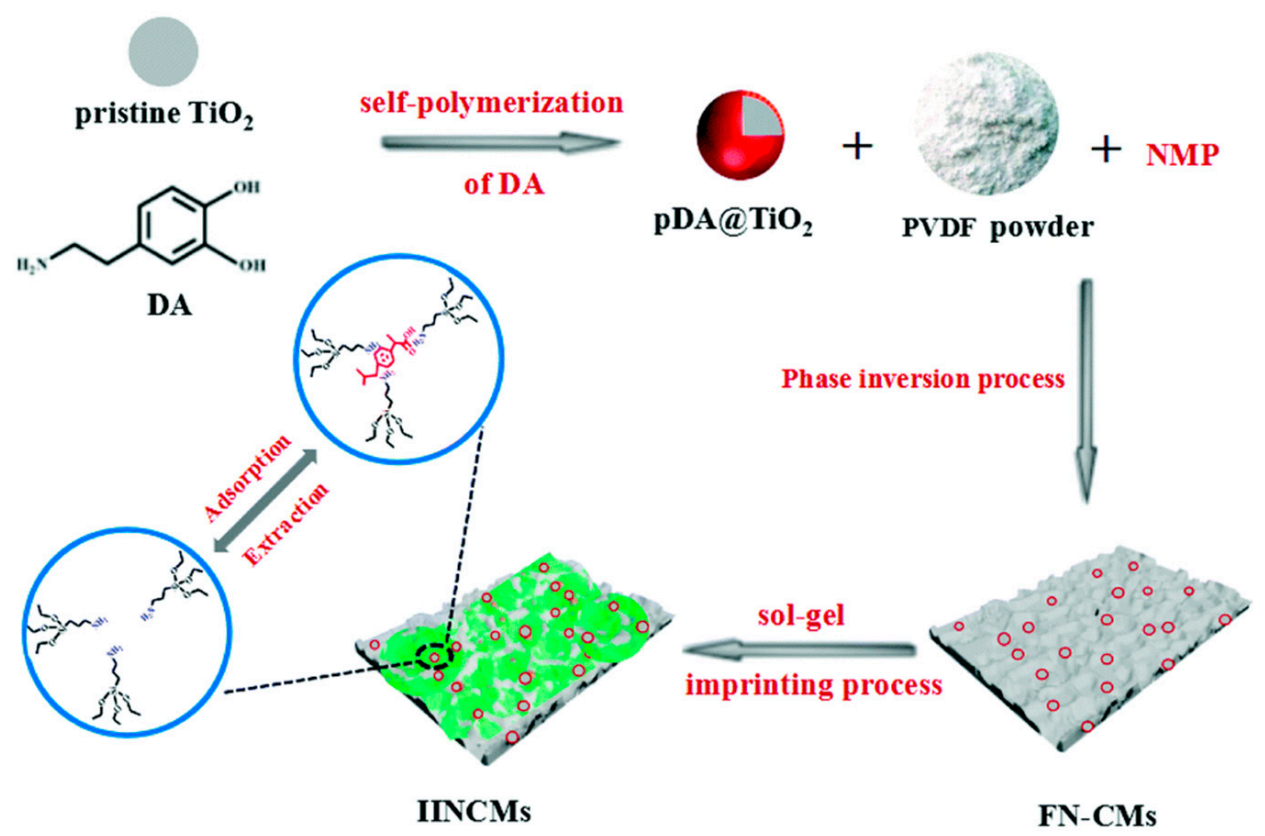

Figure 14. Schematic illustration of the procedures used to construct imprinted nanocomposite membranes with pDA@TiO2 microspheres for the selective recognition of ibuprofen. Reproduced with permission from [56]. 
Also, MIMs can be employed to remove undesirable products derived from the incomplete conversion of raw materials used in the synthesis of pharmaceutical active ingredients. As an example, Sun et al. [58] developed a MIM that could be used for the selective separation of phenol from salicylic acid (SA) for ensuring the purity of SA product. The MIM was synthesized using the breath figure method with a styrene-acrylonitrile copolymer as the membrane matrix and MIP nanoparticles (Figure 15). Thus, the nano-MIPs were first synthesized by oil-in-water emulsion polymerization using 4-vinyl pyridine (4-VP), methyl methacrylate (MMA) or cinnamic acid as the functional monomer, respectively. Then, the mixture solution was obtained by dissolving matrix and nano-MIPs in chloroform. Casting the mixture solution on a substrate under a nitrogen flow, the microporous membrane with binding sites was obtained after complete evaporation of solvent. The results revealed that the 4-VP-MIM containing $2.0 \mathrm{wt} . \%$ of nano-4-VP-MIPs exhibited the highest separation selectivity for the template phenol, whose selectivity factors relative to SA and p-hydroxybenzoic acid were 5.68 and 5.54, respectively.

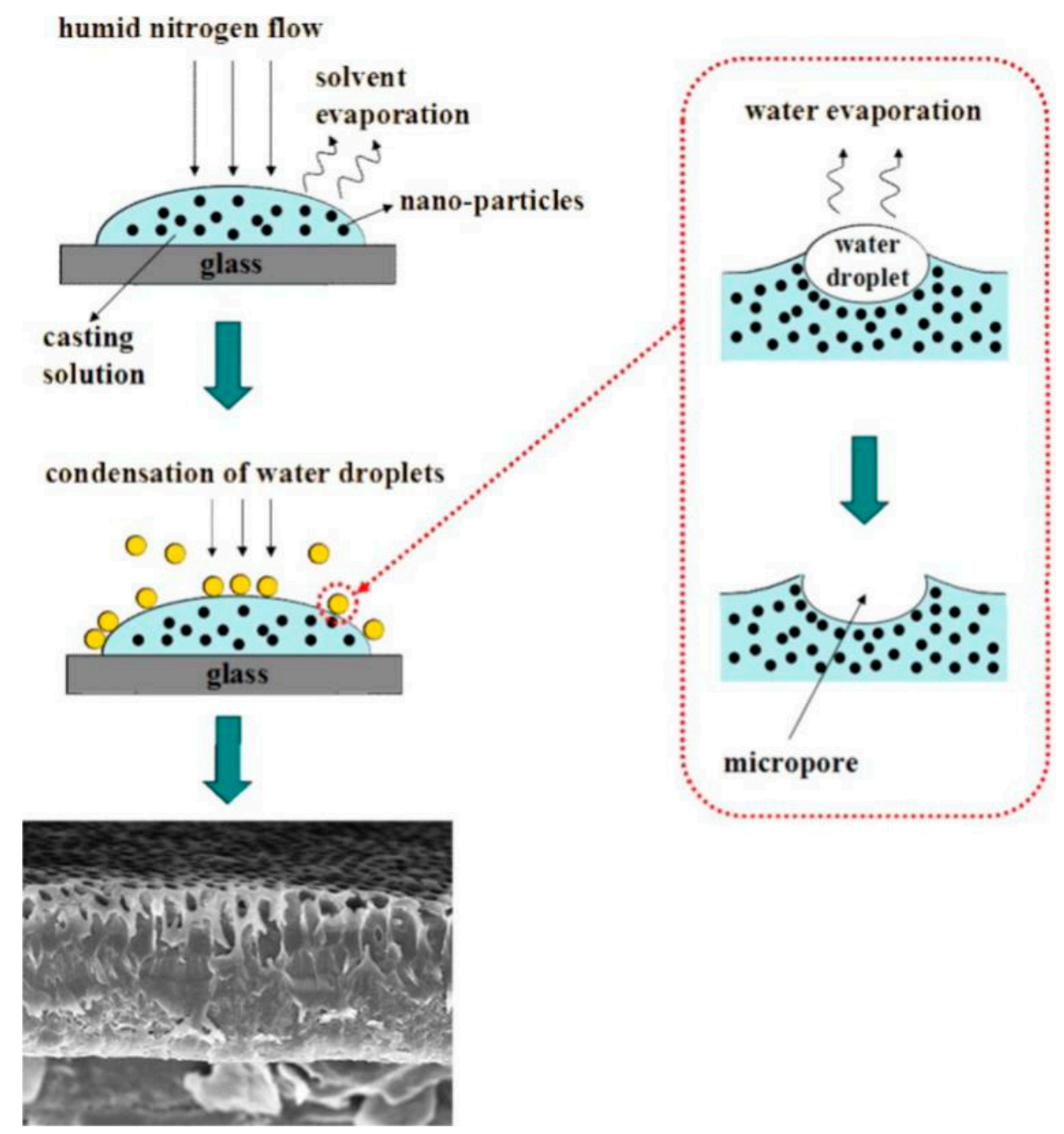

Figure 15. Schematic illustration of the preparation of a MIM by breath figure method. Reprinted with permission from ref [58].

Also, different membranes were prepared for application in the biomedical field or for various biotechnological uses, on account of their biomimetic behavior. For example, cholesterol removal studies using MIMs $[59,60]$ have become more attractive to overcome its deleterious effects on human health. Thus, Niesa et al. [60] developed a MIM obtained by in situ photopolymerization for extraction 
of cholesterol from blood samples. The MIM was prepared using cholesterol as template, MAA, EGDMA and 2-2-dimethoxy-2-phenylacetophenone. The synthesized device was able to adsorb 57\% of the cholesterol from blood samples from patients with high cholesterol levels $\left(298 \mathrm{mg} \mathrm{dL}^{-1}\right)$.

Furthermore, MIMs were used for chiral recognition of amino acids [61,62]. For example, Gao et al. [62] prepared a MIM for L-glutamic acid (L-glu) with an innovative surface imprinting strategy. By using a chemical initiating system $\left(-\mathrm{NH}_{2} / \mathrm{S}_{2} \mathrm{O}_{8}\right.$ - system), the functional monomer dimethylaminoethyl methacrylate (DMAEMA) and the crosslinking agent $\mathrm{N}, \mathrm{N}^{\prime}$-methylenebisacrylamide (MBA) produced graft/crosslinking-polymerization on the surface of aminated PSf membrane, being L-Glu molecules wrapped within the grafted polymer layer. The resulting MIM displayed a high selectivity factor of 7.52 for L-Glu relative to the other enantiomer D-Glu, and the optical purity of a penetrating fluid of the racemic mixture can reach $82 \%$, fully revealing that MIM has excellent enantioseparation ability.

Another field of recent application of MIMs was focused on the removal or depletion of abundant proteins in blood (i.e., albumin, IgG), since these components mask the low level of valuable biomarkers (such as cytokines, troponins, etc.) used in diagnosis diseases. Thus, MIMs were used for the depletion of albumin from neat solutions and biological samples [63-66]. An interesting example is that developed by Fan et al. [65], where a supermacroporous MIM was prepared via cryopolymerization using a functionalized ionic liquid \{(1-vinyl-3-(2-amino-2-oxoethyl) imidazolium chloride, [VAMIM]Cl]\} as functional monomer and bovine serum albumin (BSA) as the template. The preparation scheme of this imprinted membrane and the schematic representation of the molecular imprinting procedures were depicted in Figure 16. The resulting membrane showed several advantages such as easy mass transport of cryogel and multiple interactions of ionic liquid with protein. The results of adsorption and permeation studies confirmed that MIM had better selective recognition and perm-selectivity for BSA than NIM.

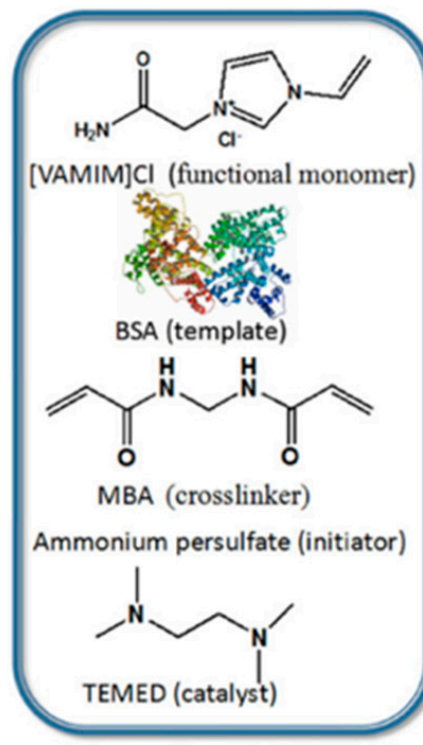

(a) (d) Valia-Chien permeation cells
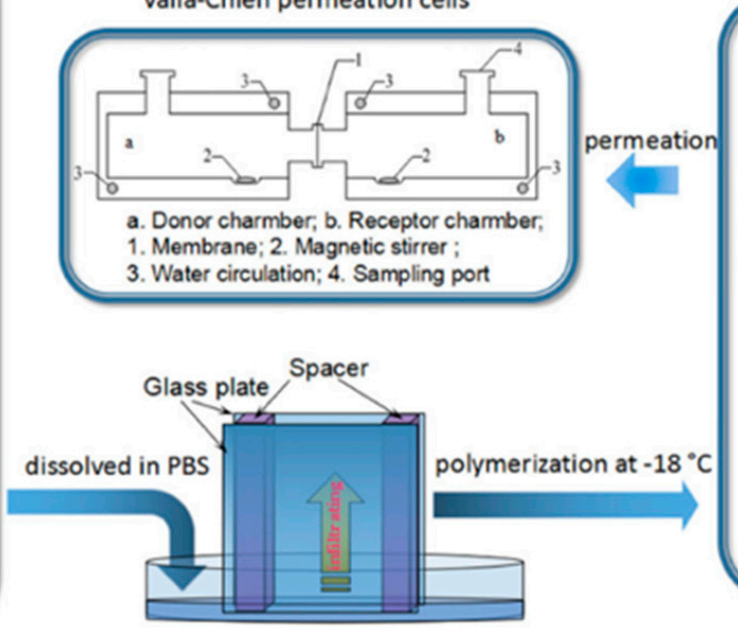

(b)

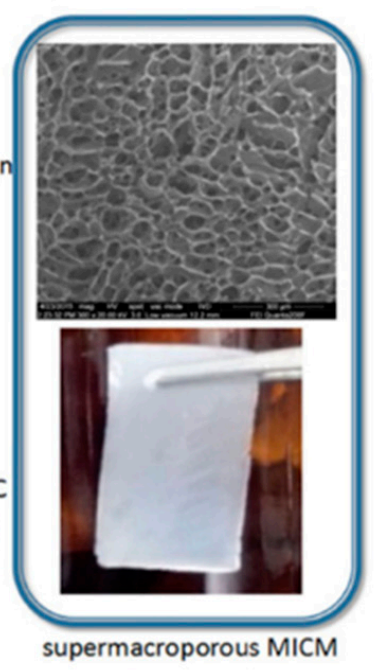

(c)

Figure 16. (a) Reagents used in the preparation of molecularly imprinted cryogel membrane; (b) schematic illustration of the infiltration of pre-polymerization solution between two glass plates; (c) the digital photograph (lower) and SEM micrograph (upper) of MIM); (d) schematic illustration of Valia-Chien permeation cells. Reprinted with permission from ref [65].

In the pharmaceutical and food industries, the extraction of polyphenols (such as flavonoids) from vegetable or food materials has gained great importance due to several associated health benefits of these compounds [67]. In this context, several MIMs were reported to separate and recover polyphenol compounds from these matrices [22,68,69]. Thus, Mansour et al. [22] synthesized MIMs 
via encapsulation of prepared quercetin-MIP NPs to recover these valuable compounds from food solid wastes extracts. The binding capacity of the resulting MIM was found to be $80 \mathrm{mmol} \mathrm{g}^{-1}$, and it was satisfactorily applied to recover various polyphenols from orange (56.1-98.8\%), lemon (44-99.3\%) and onion (64.7-94\%) peel extracts with different extraction efficiencies.

\subsection{Environmental Applications}

Due to the biological and environmental impact of metal ions, the development of novel MIMs for separation and purification of these compounds was reported [70-72]. Thus, Lu et al. [72] developed thermosensitive imprinted nanocomposite membranes for the selective separation of europium ions. The authors prepared GO-based hybrid membranes by synergistically stacking GO nanosheets and modified silica nanospheres on the membranes previously modified by pDA. AgNPs were grafted on the surface of the membranes to provide anti-fouling ability. Then, temperature-controlled selective recognition sites were formed using N-isopropylacrylamide (NIPAm) and acrylamide (Am) as functional monomers, as well as europium ions as templates through a RAFT (reversible addition-fragmentation chain transfer) method. Competitive adsorption and perm-selectivity studies were performed for the $\mathrm{Eu}(\mathrm{III}) / \mathrm{La}(\mathrm{III}), \mathrm{Eu}(\mathrm{III}) / \mathrm{Gd}(\mathrm{III}), \mathrm{Eu}(\mathrm{III}) / \mathrm{Sm}(\mathrm{III}))$ binary mixed systems, showing the imprinted membranes a high adsorptive selectivity toward target ions. The as-prepared MIM showed a satisfactory reusability (10 re-uses) and good potential in the separation of rare earth ions from wastewater.

Membrane technology was also expanded to other organic pollutants, such as herbicides [73,74], phenols (including endocrine disruptors) [75-78], aromatic hydrocarbons [79-83], dyes [84,85], and antibiotics $[86,87]$, among others. Several representative examples of these applications will be described below.

Söylemez et al. [74] developed a selective MIM for 2,4-dichlorophenoxyacetic acid (2,4-D) for its application in real water samples. The 2,4-D imprinted membranes were synthesized by $\gamma$-radiation induced in situ membrane preparation method. The as-prepared membranes showed an imprinting factor of 3.1 for the target analyte, whereas this value was below 1.3 for other structurally related compounds. The binding capacity of the MIM was $23.0 \mu \mathrm{mol} \mathrm{g}^{-1}$, an acceptable reusability (at least seven times), and it was able to remove approx. $75 \%$ of this herbicide from contaminated water samples.

Thus, Wolska et al. [76] developed a MIM on porous PP filters for removal of bisphenol A (BPA). For this purpose, the authors imprinted a layer of MMA and EGDMA via plasma-induced grafting. The obtained molecularly imprinted devices could selectively remove this analyte, being inactive in sorption of other phenol compounds. The MIM reached an adsorption value of $0.06 \mathrm{mmol} \mathrm{g}^{-1}$ and it was able to remove BPA at 70\% level from $0.2 \mathrm{mM}$ BPA aqueous solution.

Zheng et al. [80] prepared molecularly imprinted cellulose membranes for pervaporation separation of xylene isomers. The MIMs were prepared using 1,2-dihydroxybenzene as template molecule via phase inversion. The resulting membranes selectively incorporated o-xylene from o-/mand o-/p- mixtures at a low o-xylene concentration region, being the adsorption selectivity toward o-xylene 7.15 and 4.24 , respectively.

Also, removal of persistent organic pollutant from environmental compartments is a major issue to public health and environmental concern. For instance, Mkhize et al. [82] developed MIMs for selective removal of polychlorinated biphenyls (PCBs) in environmental waters. The membranes were obtained from casting the viscous solutions of MIPs, PSf and N-methyl-2-pyrrolidone (NMP) as the casting solvent. Competitive selectivity of the MIMs toward PCBs was evaluated using structurally similar compounds to PCBs (such as anthracene and $\mathrm{p}, \mathrm{p}^{\prime}$-DDT). The results showed that MIM exhibited high selectivity to PCBs, being able to achieve removal efficiencies ranged between 71.5 to $94 \%$ in spiked environmental water samples.

Another interesting example is that described by Mujahid and co-workers [83] focused on removing organosulfur compounds (like dibenzothiophene, DBTh) from fuel both to improve the performance of engines' catalytic exhaust system as well as to control SOx emissions. For this purpose, MIMs were prepared in the absence and in the presence of NiS nanoparticles as suitable affinity 
material in poly(methyl methacrylate) (PMMA) matrix (Figure 17). Both MIP and MIP-NiS membranes showed excellent desulfurization capability with $84 \%$ and $97 \%$ sulfur removal. The overall amount of sulfur removed by MIP $\left(184 \mu \mathrm{g} \mathrm{g}^{-1}\right)$ and MIP-NiS $\left(215 \mu \mathrm{g} \mathrm{g}^{-1}\right)$ is respectively about 2.6 and 3.0 times higher than the NIP $\left(72 \mu \mathrm{g} \mathrm{g}^{-1}\right)$. This result was attributed to the imprinting effects and inherent tendency of NiS nanoparticles to interact with these compounds. The developed method embodies a sustainable and viable strategy for efficient desulfurization compared to conventional methods.
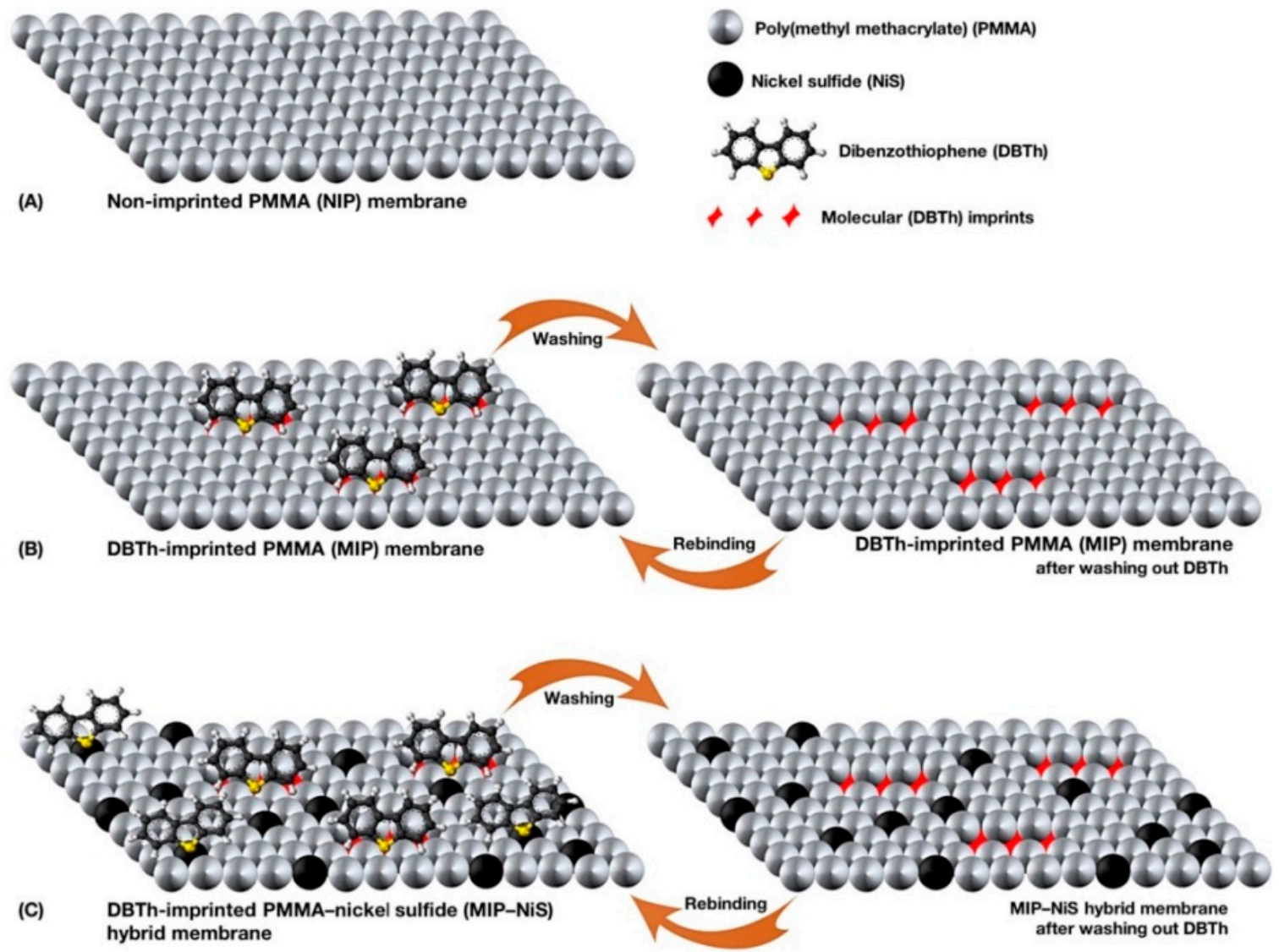

Figure 17. Scheme of the different types of membranes used for adsorptive desulfurization: (A) Non-imprinted PMMA membrane, (B) molecularly imprinted PMMA membrane formed by post-polymerization imprinting of dibenzothiophene (DBTh) in PMMA, (C) MIP-NiS hybrid membrane formed by simultaneous post-polymerization imprinting and integration of NiS nanoparticles. Reproduced with permission from ref. [83].

Lu et al. [84] developed MIMs intended to an efficient removal of dyes in lake water. Using layered double hydroxides (LDH) as the template matrix or substrate, the authors prepared Rhodamine B (RhB)-MIMs by an ATRP method (Figure 18). The resulting material had an ultra-thin membrane structure of about $1 \mathrm{~nm}$, presented a high adsorption capacity $\left(100.1 \mathrm{mg} \mathrm{g}^{-1}\right)$ and adequate selectivity. The applicability of the MIM was demonstrated by recovering RhB from spiked lake water samples, achieving removal efficiencies greater than $90 \%$.

Also, antibiotic pollutants in water have received remarkable attention due to the untold damage to human health and environment. As an example, Zhao et al. [86] prepared composite membranes using GO/PVDF blended membranes as substrates for selective separation of norfloxacin from aqueous solution. In particular, the as-prepared GO/PVDF blended membranes were used as platform to immobilize $\mathrm{TiO}_{2}$ nanospheres, which were modified by a functionalization process with KH570 for further imprinting process. The as-prepared nanocomposite membrane showed great selectivity (selectivity coefficient obtained up to 7.35) and permeability (permeability factor above 
6.0). Furthermore, the membrane exhibited satisfactory adsorption capacity $\left(44.81 \mathrm{mg} \mathrm{g}^{-1}\right)$ and an acceptable reusability (at least six adsorption/desorption cycles). Other interesting example is that described by Xing et al. [87], who developed sustainable molecularly imprinted nanocomposite membranes for the selective recognition of tetracycline (TC). Thus, biomass-activated carbon NPs were integrated into porous CA/CS membranes to synthesize renewable basal membranes with enhanced adsorption capacity and permeation flux. The specific recognition sites were fabricated from simple free radical polymerization method, using MAA and Am as functional monomers, and TC as template. The results indicated that the as-prepared hybrid MIMs exhibited desirable biodegradability, satisfactory adsorption (15.99 $\mathrm{mg} \mathrm{g}^{-1}$ ) and good separation performance (perm-selectivity factor 2.4).

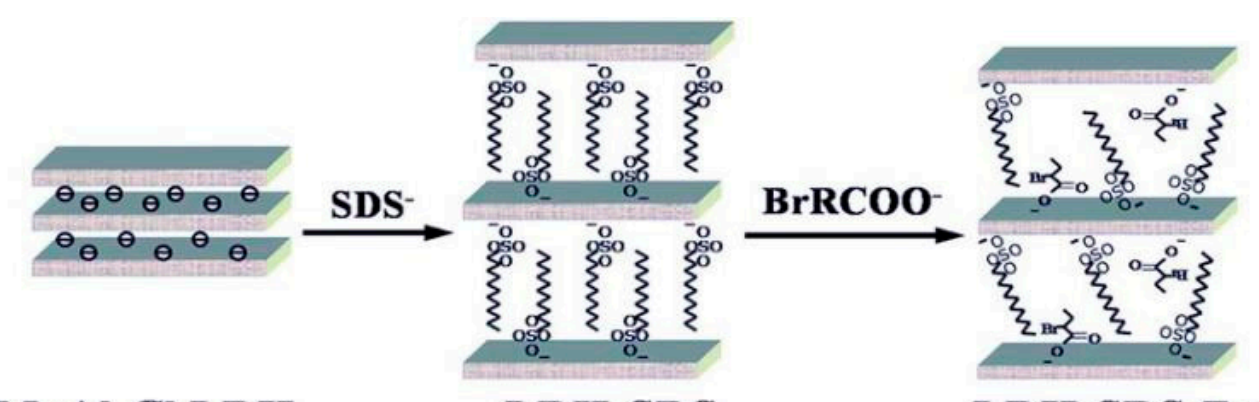

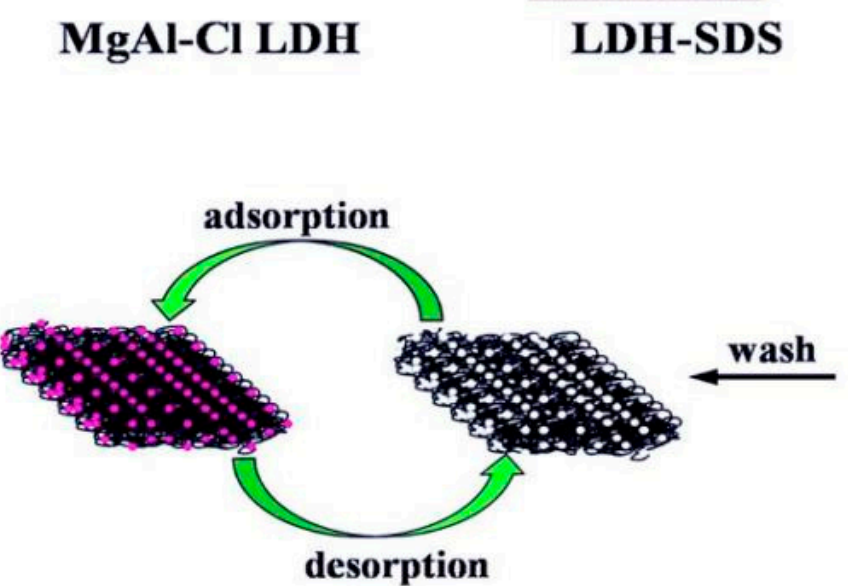

MIPs-RhB

MIPs

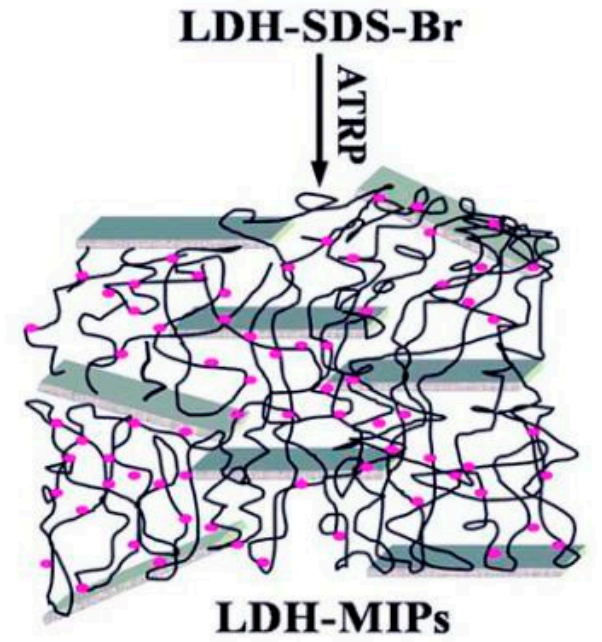

Figure 18. Preparation of ultra-thin MIPs membranes for RhB. Reproduced with permission from ref. [84]. 
Table 2. Recent applications of MIMs in separation processes in pharmaceutical and food field.

\begin{tabular}{|c|c|c|c|c|c|c|c|c|}
\hline Analyte(s) & $\begin{array}{l}\text { Template/Monomer/ } \\
\text { Crosslinker/Solvent }\end{array}$ & Substrate & Imprinting Technique & Matrix & $\begin{array}{l}\text { Determination } \\
\text { Technique }\end{array}$ & IF/SF & PSF & Reference \\
\hline 2-AP & 2-AP/-/-/DMAc: $\mathrm{H}_{2} \mathrm{O}$ & PBI & Phase inversion & - & HPLC-UV & $4.1 / 5.5$ & 3.9 & [23] \\
\hline Paclitaxel & Paclitaxel/-//DMF & PSf & Phase inversion & $\begin{array}{l}\text { Yew tree } \\
\text { extract }\end{array}$ & HPLC-UV & $2.28 /-$ & - & [52] \\
\hline Matrine & Matrine/MAA/EGDMA/ $\mathrm{H}_{2} \mathrm{O}: \mathrm{MeOH}$ & CMPSf & Surface grafting & - & UV & $140 / 4.85$ & 5.9 & [50] \\
\hline Ars & Ars/Am/EGDMA/Pyridine & PVDF & Surface grafting & - & HPLC-UV & $14.9 / 2.04$ & 5.6 & [51] \\
\hline Propranolol & Propranolol/MAA/MBA/ $\mathrm{H}_{2} \mathrm{O}$ & $\begin{array}{l}\text { Br-Ag-pDA@SiO }{ }_{2} \text {-based } \\
\text { composite PVDF }\end{array}$ & Surface grafting & - & HPLC-UV & $4.85 / 2.70-3.24$ & $5.52-6.71$ & {$[53]$} \\
\hline Propranolol & $\begin{array}{l}\text { Propranolol/MAA, } \\
\text { AM/MBA/EtOH }\end{array}$ & $\begin{array}{l}\mathrm{GO} / \mathrm{TiO}_{2} \text {-based } \\
\text { composite } \mathrm{RC}\end{array}$ & Surface grafting & - & HPLC-UV & $\begin{array}{c}4.26 / \\
3.0-3.2\end{array}$ & $11.35-13.66$ & [54] \\
\hline Ibuprofen & Ibuprofen/APTES/TEOS/EtOH & $\begin{array}{l}\text { pDA@GO-based } \\
\text { composite PVDF }\end{array}$ & Surface grafting & - & UV & $4.38 / 3.51-3.91$ & $6.55-6.63$ & [55] \\
\hline Ibuprofen & Ibuprofen/APTES/TEOS/EtOH & $\begin{array}{l}\text { pDA@TiO }{ }_{2} \text {-based } \\
\text { composite PVDF }\end{array}$ & Surface grafting & - & UV & $4.68 / 3.25-3.66$ & $4.42-4.46$ & [56] \\
\hline Tetracycline & Tetracycline/MAA/EGDMA/ $\mathrm{H}_{2} \mathrm{O}$ & $\begin{array}{c}\mathrm{Ag} / \mathrm{pDA} @ \mathrm{Al}_{2} \mathrm{O}_{3} \text { ceramic } \\
\text { membrane }\end{array}$ & Surface grafting & - & UV & $2.64 / 3.27-3.60$ & $5.95-6.15$ & [57] \\
\hline Phenol & Phenol/4-VP/DVB/MeOH & SAN & $\begin{array}{l}\text { In situ polymerization } \\
\text { (embedded membrane) }\end{array}$ & - & UV & $5.54-5.68$ & - & [58] \\
\hline Cholesterol & $\begin{array}{c}\text { Cholesterol/MTrp, } \\
\text { HEMA/EGDMA/MeOH }\end{array}$ & HEMA & $\begin{array}{l}\text { In situ polymerization } \\
\text { (embedded membrane) }\end{array}$ & $\begin{array}{l}\text { Intestinal } \\
\text { mimic } \\
\text { solution }\end{array}$ & HPLC-UV & $2.04-2.39$ & - & [59] \\
\hline Cholesterol & Cholesterol/MAA/EGDMA/ACN & - & In situ polymerization & Blood & UV & - & - & {$[60]$} \\
\hline D-Tryptophan & D-Tryptophan/-/ $/ \mathrm{CaCl}_{2} / \mathrm{H}_{2} \mathrm{O}$ & SAg & Phase inversion & - & HPLC-UV & - & - & [61] \\
\hline L-glu & L-glu/DMAEMA/MBA/DMF- $\mathrm{H}_{2} \mathrm{O}$ & CMPSf & Surface grafting & - & UV & $1.44 / 7.52$ & 3.25 & [62] \\
\hline BSA & (pDA)-BSA/-/-/ $\mathrm{H}_{2} \mathrm{O}$ & $\mathrm{CS} / \mathrm{PVP} / \mathrm{MWCNTS}$ & Phase inversion & $\begin{array}{l}\text { Bovine } \\
\text { blood }\end{array}$ & Fluorescence & $2.80 / 1.73-2.14$ & - & [63] \\
\hline BSA & BSA/ HEMA-MAP/EGDMA/PBS & - & In situ polymerization & - & UV & $3.74 / 1.12-1.34$ & - & {$[64]$} \\
\hline BSA & BSA/VAMIN/MBA/PBS & - & In situ cryo-polymerization & Blood & UV & $2.37 / 1.33-2.35$ & 1.73 & [65] \\
\hline BSA; Lys & BSA or Lys/MMA/EGDMA/NMP & $\mathrm{CA}$ & Surface grafting & Cell broth & HPLC-UV & $\begin{array}{c}2.39-4.23 / \\
-\end{array}$ & $4-9$ & [66] \\
\hline Kaempferol & Kaempferol/4-VP/EGDMA/ACN & PPSU & Phase inversion & - & UV & 4.12 & - & {$[68]$} \\
\hline Quercetin & $\begin{array}{l}\text { Quercetin/HEMA-MAH/EGDMA/ } \\
\text { isopropyl alcohol }\end{array}$ & - & In situ polymerization & - & UV & $30.6 /-$ & - & [69] \\
\hline Polyphenols & Quercetin/AN/EGDMA/ACN & $\mathrm{CA}$ & $\begin{array}{l}\text { In situ polymerization } \\
\text { (embedded membrane) }\end{array}$ & $\begin{array}{l}\text { Lemon, } \\
\text { orange and } \\
\text { onion peels }\end{array}$ & HPLC-UV & - & - & [22] \\
\hline
\end{tabular}

2-AP: 2 aminopyridine; 4-VP: 4-vinyl pyridine; Ars: artemisinin; AM: acrylamide, AN: acrylonitrile; APTES: 3-amino-propyltriethoxysilane; BSA: bovine serum albumin; CMPSf: chloromethylated polysulfone; DMAc: N,N-dimethylacetamide; DMAEMA: dimethylaminoethlyl methacrylate; EtOH: Ethanol; GO: graphene oxide; HEMA: hydroxyethyl methacrylate; IF: imprinting factor; L-glu: L-glutamic acid; Lys: lysine; MAH: N-methacryloyl-(L)-histidine; MAP: N-methacryloyl-(L)-phenylalanine methyl ester; MBA: N,N-methylenebis(acrylamide); MMA: methyl methaacrylate; MTrp: N-methacryloyl-1-tryptophan methylester; MWCNT: multi-walled carbon nanotube; NMP: N-methyl-2-pyrrolidone; PBI: polybenzimidazole; PBS: Phosphate Buffer Solution; pDA: polydopamine; PPSU: polyphenylene sulfone; PSF: permselectivity factor; PSf: polysulfone; PVP: polyvinyl pyrrolidone; SAg: sodium alginate; SAN: styrene-acrylonitrile; SF: selectivity factor; TEOS: tetraethyl orthosilicate; VAMIM: 1-vinyl-3-(2-Amino-2-oxoethyl)imidazolium chloride. 
Table 3. Recent applications of MIMs in separation processes in environmental field.

\begin{tabular}{|c|c|c|c|c|c|c|c|c|}
\hline Analyte(s) & $\begin{array}{l}\text { Template/Monomer/ } \\
\text { Crosslinker/Solvent }\end{array}$ & Substrate & Imprinting Technique & Matrix & $\begin{array}{l}\text { Determination } \\
\text { Technique }\end{array}$ & IF/SF & PSF & Referemce \\
\hline $\mathrm{Pb}^{2+}$ & $\mathrm{Pb}\left(\mathrm{NO}_{2}\right)_{3} / \mathrm{PAA} / \mathrm{GLA} / \mathrm{H}_{2} \mathrm{O}$ & PVA & $\begin{array}{l}\text { In situ polymerization } \\
\text { (embedded membrane) }\end{array}$ & - & ICP-OES & $1.25 / 70$ & - & [70] \\
\hline $\mathrm{Li}^{+}$ & $\mathrm{Li}^{+} / 12 \mathrm{C} 4, \mathrm{MAA}, \mathrm{EGDMA} / \mathrm{ACN}$ & PES & Surface grafting & - & ICP-OES & $2.55 / 1.85-2.07$ & $7.39-9.86$ & [71] \\
\hline $\mathrm{Eu}^{3+}$ & $\mathrm{Eu}^{3+} / \mathrm{NIPAm}, \mathrm{Am} / \mathrm{EGDMA} / \mathrm{ACN}$ & RCM & Surface grafting & - & ICP-OES & $4.09 / 1.45-1.82$ & $3.34-3.82$ & [72] \\
\hline 2,4-D & 2,4-D/MAA/TRIM/DMAc & PSf & Phase inversion & - & UV & $-/ 12.96$ & 1.7 & [73] \\
\hline $2,4-\mathrm{D}$ & $\begin{array}{l}\text { 2,4-D/N-vinylimidazole/EGDMA/ } \\
\text { MeOH:water }\end{array}$ & - & In situ polymerization & Water & UV & $\begin{array}{c}1.1-3.1 / \\
2.35-2.74\end{array}$ & - & [74] \\
\hline Phenol & Phenol/MAA/TRIM/ACN & PSf & Phase inversion & - & UV & $1.08 / 3.57$ & - & [75] \\
\hline BPA & BPA/MMA/EGDMA/n-octane & PP & Plasma-induced grafting & - & UV & $2.9-9 /-$ & $32.2-78.3$ & [76] \\
\hline 4-Nitrophenol & 4-Nitrophenol/-/GLA/PEG & CS & In situ polymerization & Water & HPLC-UV & $1.52 / 2.46-16.19$ & - & [77] \\
\hline $\mathrm{m}$-Cresol & m-Cresol/APTES/TEOS/EtOH & $\mathrm{RCM}$ & Surface grafting & - & HPLC-UV & $3.07 / 4.41-5.41$ & $13.17-15.44$ & [78] \\
\hline Xylene isomers & $\begin{array}{l}\text { 1,2-dihydroxybenzene } \\
\text { /-/LiCl/DMAc }\end{array}$ & $\mathrm{CM}$ & Phase inversion & - & UV & $-/ 4.24-7.15$ & - & [80] \\
\hline PAHs & Anthracene/MAA/EGDMA/ACN & CA & Phase inversion & - & HPLC-UV & $-/ 5-18.8$ & - & [81] \\
\hline Naphthalene & Naphthalene/-/DMF & PSf & Phase inversion & $\begin{array}{l}\text { Wastewater } \\
\text { streams }\end{array}$ & UV & $1.28 / 2.27$ & - & [79] \\
\hline PCBs & Anthracene/MAA/EGDMA/ACN & PSf & Phase inversion & Water & CG-TOF-MS & - & $8.23-10.3$ & [82] \\
\hline DBTu & $\mathrm{DBTu} / \mathrm{PMMA} / \mathrm{CHCl}_{3}$ & - & In situ polymerization & - & UV & $2.60-3.0 /-$ & - & [83] \\
\hline RhB & RhB/MAA/EGDMA/ACN & LDH-based material & Surface grafting & Water & UV & $2.83 / 8.8-27.3$ & - & [84] \\
\hline MB & MB/MAA/MBA/THF & PSf & Phase inversion & - & UV & - & $2.83-2.91$ & [85] \\
\hline Norfloxacin & Norfloxacin/Am/EGDMA/EtOH & $\mathrm{TiO}_{2} @ \mathrm{GO} / \mathrm{PVDF}$ & Surface grafting & Water & UV & $5.73 / 5.45-7.35$ & 6.25 & [86] \\
\hline $\mathrm{TC}$ & TC/MAA, Am/EDGMA/EtOH & $\begin{array}{l}\text { ACNPs@ } \\
\text { CA/CS }\end{array}$ & Surface grafting & Water & HPLC-UV & $3.3-3.6 / 3.4$ & 2.4 & [87] \\
\hline
\end{tabular}

12C4: 12-crown-4; BPA: bisphenol A; DBTu: dibenzothiophene; GLA: glutaraldehyde; LDH: layered double hydroxides; MB: Methylene blue; NIPAm: N-isopropylacrylamide; NPs: nanoparticles; PAA: polyacrylic acid; PCB: Polychlorinated biphenyl; PEG: poly ethylenglycol; PMMA: poly(methyl methacrylate); PVA: poly(vinyl alcohol); RCM: regenerated cellulose membrane; RhB: rhodamine B; TC: tetracycline; THF: tetrahydrofuran; TRIM: trimethylolpropane trimethacrylate. 


\section{Conclusions}

The recent advances of combination of molecular imprinting and membrane technology to prepare MIMs with affinity properties for sample treatment and separation processes were reviewed here. Compared with traditional application of imprinted materials in sample treatment and other areas, which involve the use of imprinted polymer particles, MIMs offer several benefits. These materials take advantage of features of membrane separation technology (such as continuous operation, low energy consumption, and high efficiency of transport), which make them more convenient and robust to operate in the clean-up procedure and industrial separation processes. Besides, the MIMs provide larger specific surface area with relatively high imprinting sites per unit mass, less consumption of chemical reagents and reduction of sample treatment time. A variety of MIM synthesis procedures were employed such as in situ polymerization, phase inversion and surface imprinting, being this latter strategy a popular and convenient technique due its flexibility, easy accessibility of the recognition sites and favorable binding kinetics. Because of their versatility, several applications of MIMs comprising sample pretreatment field as well as separation/purification processes of different targets (such as drugs, pollutants, proteins, among others) were described.

Despite the great application potential of these materials, we are aware that there are still great challenges for their further development. For instance, one of them is to achieve a homogeneous distribution of imprinted recognition sites, which has a relevant influence on the selectivity and adsorption capacity of final MIMs. Hence, the thickness homogeneity of the MIP layer on MIMs is a non-negligible factor that would need more consideration, and more research toward the controllable synthesis of MIMs would be desirable. Imprinting polymerization method is a key factor affecting the imprinting effect. As we mentioned above, the preparation of MIMs based on diverse polymerization methods can be accomplished. However, some harsh reaction conditions and long polymerization time can cause damage of membranes in terms of physicochemical properties or microstructures, thus affecting the final performance of MIMs. In this sense, novel fabrication strategies (for example, click chemistry) with mild and simple conditions are desired for the preparation of MIMs. It can be expected that the improvement of imprinting polymerization methods will significantly facilitate the in-depth research and wide applications of MIMs. Also, other great challenge for research in this field is the production of MIMs with virus, which could be used in diagnosis and therapeutic treatments.

In summary, all the developments in MIMs that are expected to happen in the future will positively aid both to enhance the use of these materials in analytical chemistry, biotechnology, health care, environmental protection, and industrial development areas as well as to expand its applications to other fields in the upcoming years.

Author Contributions: All authors participated in the bibliographic review, manuscript writing and revision. All authors have read and agreed to the published version of the manuscript.

Funding: This work was supported by project RTI2018-095536-B-I00 (Ministry of Science, Innovation and Universities, Spain).

Conflicts of Interest: The authors declare no conflict of interest.

\section{References}

1. Chen, L.; Wang, X.; Lu, W.; Wu, X.; Li, J. Molecular imprinting: Perspectives and applications. Chem. Soc. Rev. 2016, 45, 2137-2211. [CrossRef]

2. Chen, L.; Xu, S.; Li, J. Recent advances in molecular imprinting technology: Current status, challenges and highlighted applications. Chem. Soc. Rev. 2011, 40, 2922. [CrossRef]

3. Mayes, A.G.; Whitcombe, M.J. Synthetic strategies for the generation of molecularly imprinted organic polymers. Adv. Drug Deliv. Rev. 2005, 57, 1742-1778. [CrossRef]

4. Cieplak, M.; Szwabinska, K.; Sosnowska, M.; Chandra, B.K.C.; Borowicz, P.; Noworyta, K.; D'Souza, F.; Kutner, W. Selective electrochemical sensing of human serum albumin by semi-covalent molecular imprinting. Biosens. Bioelectron. 2015, 74, 960-966. [CrossRef] 
5. Ghorbani, M.; Aghamohammadhassan, M.; Chamsaz, M.; Akhlaghi, H.; Pedramrad, T. Dispersive solid phase microextraction. TrAC Trends Anal. Chem. 2019, 118, 793-809. [CrossRef]

6. Sari, E.; Üzek, R.; Merkoçi, A. Paper Based Photoluminescent Sensing Platform with Recognition Sites for Tributyltin. ACS Sens. 2019, 4, 645-653. [CrossRef] [PubMed]

7. Yang, S.; Wang, Y.; Jiang, Y.; Li, S.; Liu, W. Molecularly imprinted polymers for the identification and separation of chiral drugs and biomolecules. Polymers 2016, 8, 216. [CrossRef] [PubMed]

8. Cheong, W.J.; Yang, S.H.; Ali, F. Molecular imprinted polymers for separation science: A review of reviews. J. Sep. Sci. 2013, 36, 609-628. [CrossRef]

9. Gilart, N.; Borrull, F.; Fontanals, N.; Marcé, R.M. Selective materials for solid-phase extraction in environmental analysis. Trends Environ. Anal. Chem. 2014, 1, e8-e18. [CrossRef]

10. Schirhagl, R. Bioapplications for molecularly imprinted polymers. Anal. Chem. 2014, 86, 250-261. [CrossRef]

11. Speltini, A.; Scalabrini, A.; Maraschi, F.; Sturini, M.; Profumo, A. Newest applications of molecularly imprinted polymers for extraction of contaminants from environmental and food matrices: A review. Anal. Chim. Acta 2017, 974, 1-26. [CrossRef] [PubMed]

12. Madikizela, L.M.; Ncube, S.; Chimuka, L. Recent Developments in Selective Materials for Solid Phase Extraction. Chromatographia 2019, 82, 1171-1189. [CrossRef]

13. Turiel, E.; Martín-Esteban, A. Molecularly imprinted polymers-based microextraction techniques. TrAC-Trends Anal. Chem. 2019, 118, 574-586. [CrossRef]

14. Yoshikawa, M.; Tharpa, K.; Dima, Ş.-O. Molecularly Imprinted Membranes: Past, Present, and Future. Chem. Rev. 2016, 116, 11500-11528. [CrossRef]

15. Boysen, R.I.; Schwarz, L.J.; Nicolau, D.V.; Hearn, M.T.W. Molecularly imprinted polymer membranes and thin films for the separation and sensing of biomacromolecules. J. Sep. Sci. 2017, 40, 314-335. [CrossRef]

16. Meng, L.; Turner, A.P.F.; Mak, W.C. Soft and flexible material-based affinity sensors. Biotechnol. Adv. 2020, 39, 107398. [CrossRef]

17. Trotta, F.; Biasizzo, M.; Caldera, F. Molecularly imprinted membranes. Membranes 2012, 2, 440-477. [CrossRef]

18. Li, J.; Zhang, L.; Fu, C. The Recognizing Mechanism and Selectivity of the Molecularly Imprinting Membrane. In Molecularly Imprinted Catalysts; Elsevier: Amsterdam, The Netherlands, 2016; pp. 159-182. ISBN 9780128013014.

19. Piletsky, S.A.; Panasyuk, T.L.; Piletskaya, E.V.; Nicholls, I.A.; Ulbricht, M. Receptor and transport properties of imprinted polymer membranes - A review. J. Memb. Sci. 1999, 157, 263-278. [CrossRef]

20. Ulbricht, M. Membrane separations using molecularly imprinted polymers. J. Chromatogr. B Anal. Technol. Biomed. Life Sci. 2004, 804, 113-125. [CrossRef]

21. Zaidi, S.A. Molecular imprinting polymers and their composites: A promising material for diverse applications. Biomater. Sci. 2017, 5, 388-402. [CrossRef]

22. Mansour, M.S.M.; Abdel-Shafy, H.I.; Mehaya, F.M.S. Valorization of food solid waste by recovery of polyphenols using hybrid molecular imprinted membrane. J. Environ. Chem. Eng. 2018, 6, 4160-4170. [CrossRef]

23. Székely, G.; Valtcheva, I.B.; Kim, J.F.; Livingston, A.G. Molecularly imprinted organic solvent nanofiltration membranes-Revealing molecular recognition and solute rejection behaviour. React. Funct. Polym. 2015, 86, 215-224. [CrossRef]

24. Guillen, G.R.; Ramon, G.Z.; Kavehpour, H.P.; Kaner, R.B.; Hoek, E.M.V. Direct microscopic observation of membrane formation by nonsolvent induced phase separation. J. Memb. Sci. 2013, 431, 212-220. [CrossRef]

25. He, Z.; Meng, M.; Yan, L.; Zhu, W.; Sun, F.; Yan, Y.; Liu, Y. Fabrication of new cellulose acetate blend imprinted membrane assisted with ionic liquid $([\mathrm{BMIM}] \mathrm{Cl})$ for selective adsorption of salicylic acid from industrial wastewater. Sep. Purif. Technol. 2015, 145, 63-74. [CrossRef]

26. Xu, X.; Wan, L.; Huang, X. Functionalization Methods for Membrane Surfaces. In Surface Engineering of Polymer Membranes; Springer: Berlin/Heidelberg, Germany, 2009.

27. Yao, R.; Yu, Z.; Wu, M.; Yu, H. Preparation and evaluation of molecularly imprinted membrane of teicoplanin. Anal. Methods 2018, 10, 5416-5422. [CrossRef]

28. Patel, K.D.; Kim, H.W.; Knowles, J.C.; Poma, A. Molecularly Imprinted Polymers and Electrospinning: Manufacturing Convergence for Next-Level Applications. Adv. Funct. Mater. 2020, 30, 2001955. [CrossRef]

29. Liu, F.; Hashim, N.A.; Liu, Y.; Abed, M.R.M.; Li, K. Progress in the production and modification of PVDF membranes. J. Memb. Sci. 2011, 375, 1-27. [CrossRef] 
30. Wu, Y.; Yan, M.; Cui, J.; Yan, Y.; Li, C. A Multiple-Functional Ag/SiO $2 /$ Organic Based Biomimetic Nanocomposite Membrane for High-Stability Protein Recognition and Cell Adhesion/Detachment. Adv. Funct. Mater. 2015, 25, 5823-5832. [CrossRef]

31. Wu, Y.; Yan, M.; Liu, X.; Lv, P.; Cui, J.; Meng, M.; Dai, J.; Yan, Y.; Li, C. Accelerating the design of multi-component nanocomposite imprinted membranes by integrating a versatile metal—organic methodology. Green Chem. 2015, 17, 3338-3349. [CrossRef]

32. Beigzadeh, Z.; Golbabaei, F.; Khadem, M.; Omidi, F.; Someah, M.S.; Shahtaheri, S.J. Development of Molecularly Imprinted Membranes for Selective Determination of Urinary Ultra-Trace 5-Fluorouracil as Antineoplastic Drug Used in Chemotherapy. Macromol. Res. 2020, 28, 390-399. [CrossRef]

33. Yu, H.; Yao, R.; Shen, S. Development of a novel assay of molecularly imprinted membrane by design-based gaussian pattern for vancomycin determination. J. Pharm. Biomed. Anal. 2019, 175, 112789. [CrossRef] [PubMed]

34. Moein, M.M.; Javanbakht, M.; Karimi, M.; Akbari-adergani, B.; Abdel-Rehim, M. A new strategy for surface modification of polysulfone membrane by in situ imprinted sol-gel method for the selective separation and screening of L-Tyrosine as a lung cancer biomarker. Analyst 2015, 140, 1939-1946. [CrossRef] [PubMed]

35. Li, T.; Fan, L.; Wang, Y.; Huang, X.; Xu, J.; Lu, J.; Zhang, M.; Xu, W. Molecularly Imprinted Membrane Electrospray Ionization for Direct Sample Analyses. Anal. Chem. 2017, 89, 1453-1458. [CrossRef] [PubMed]

36. Tavares, L.S.; Carvalho, T.C.; Romão, W.; Vaz, B.G.; Chaves, A.R. Paper Spray Tandem Mass Spectrometry Based on Molecularly Imprinted Polymer Substrate for Cocaine Analysis in Oral Fluid. J. Am. Soc. Mass Spectrom. 2018, 29, 566-572. [CrossRef] [PubMed]

37. Sánchez-González, J.; Tabernero, M.J.; Bermejo, A.M.; Bermejo-Barrera, P.; Moreda-Piñeiro, A. Porous membrane-protected molecularly imprinted polymer micro-solid-phase extraction for analysis of urinary cocaine and its metabolites using liquid chromatography-Tandem mass spectrometry. Anal. Chim. Acta 2015, 898, 50-59. [CrossRef] [PubMed]

38. Sánchez-González, J.; García-Carballal, S.; Cabarcos, P.; Tabernero, M.J.; Bermejo-Barrera, P.; Moreda-Piñeiro, A. Determination of cocaine and its metabolites in plasma by porous membrane-protected molecularly imprinted polymer micro-solid-phase extraction and liquid chromatography—tandem mass spectrometry. J. Chromatogr. A 2016, 1451, 15-22. [CrossRef]

39. Sánchez-González, J.; Odoardi, S.; Bermejo, A.M.; Bermejo-Barrera, P.; Romolo, F.S.; Moreda-Piñeiro, A.; Strano-Rossi, S. Development of a micro-solid-phase extraction molecularly imprinted polymer technique for synthetic cannabinoids assessment in urine followed by liquid chromatography-tandem mass spectrometry. J. Chromatogr. A 2018, 1550, 8-20. [CrossRef]

40. Sánchez-González, J.; Odoardi, S.; Bermejo, A.M.; Bermejo-Barrera, P.; Romolo, F.S.; Moreda-Piñeiro, A.; Strano-Rossi, S. HPLC-MS/MS combined with membrane-protected molecularly imprinted polymer micro-solid-phase extraction for synthetic cathinones monitoring in urine. Drug Test. Anal. 2019, 11, 33-44. [CrossRef]

41. Lee, T.P.; Saad, B.; Nakajima, L.; Kobayashi, T. Preparation and Characterization of Hybrid Molecularly Imprinted Polymer Membranes for the Determination of Citrinin in Rice. Sains Malays. 2019, 48, 1661-1670. [CrossRef]

42. Moein, M.M.; Javanbakht, M.; Karimi, M.; Akbari-adergani, B. Fabrication of a novel electrospun molecularly imprinted nanomembrane coupled with high-performance liquid chromatography for the selective separation and determination of acesulfame. J. Sep. Sci. 2015, 38, 1372-1379. [CrossRef]

43. Akbari-adergani, B.; Sadeghian, G.H.; Alimohammadi, A.; Esfandiari, Z. Integrated photografted molecularly imprinted polymers with a cellulose acetate membrane for the extraction of melamine from dry milk before HPLC analysis. J. Sep. Sci. 2017, 40, 1361-1368. [CrossRef] [PubMed]

44. Pereira, I.; Rodrigues, M.F.; Chaves, A.R.; Vaz, B.G. Molecularly imprinted polymer (MIP) membrane assisted direct spray ionization mass spectrometry for agrochemicals screening in foodstuffs. Talanta 2018, 178, 507-514. [CrossRef]

45. Jayasinghe, G.D.T.M.; Domínguez-González, R.; Bermejo-Barrera, P.; Moreda-Piñeiro, A. Ultrasound assisted combined molecularly imprinted polymer for the selective micro-solid phase extraction and determination of aflatoxins in fish feed using liquid chromatography-tandem mass spectrometry. J. Chromatogr. A 2020, 1609, 460431. [CrossRef] [PubMed] 
46. Meng, M.; Bai, M.; Da, Z.; Cui, Y.; Li, B.; Pan, J. Selective recognition of salicylic acid employing new fluorescent imprinted membrane functionalized with poly(amidoamine) (PAMAM)-encapsulated Eu(TTA)3phen. J. Lumin. 2019, 208, 24-32. [CrossRef]

47. Rozaini, M.N.H.; Semail, N.; Saad, B.; Kamaruzaman, S.; Abdullah, W.N.; Rahim, N.A.; Miskam, M.; Loh, S.H.; Yahaya, N. Molecularly imprinted silica gel incorporated with agarose polymer matrix as mixed matrix membrane for separation and preconcentration of sulfonamide antibiotics in water samples. Talanta 2019, 199, 522-531. [CrossRef] [PubMed]

48. Altintas, Z.; Chianella, I.; Da Ponte, G.; Paulussen, S.; Gaeta, S.; Tothill, I.E. Development of functionalized nanostructured polymeric membranes for water purification. Chem. Eng. J. 2016, 300, 358-366. [CrossRef]

49. Ncube, S.; Lekoto, G.; Cukrowska, E.; Chimuka, L. Development and optimisation of a novel three-way extraction technique based on a combination of Soxhlet extraction, membrane assisted solvent extraction and a molecularly imprinted polymer using sludge polycyclic aromatic hydrocarbons as model compounds. J. Sep. Sci. 2018, 41, 918-928. [CrossRef]

50. Gao, B.; Zhang, L.; Li, Y. Designing and preparation of novel alkaloid-imprinted membrane with grafting type and its molecular recognition characteristic and permselectivity. Mater. Sci. Eng. C 2016, 66, 259-267. [CrossRef]

51. Cui, J.; Wu, Y.; Meng, M.; Lu, J.; Wang, C.; Zhao, J.; Yan, Y. Bio-inspired synthesis of molecularly imprinted nanocomposite membrane for selective recognition and separation of artemisinin. J. Appl. Polym. Sci. 2016, 133, 43405. [CrossRef]

52. Ghasemi, S.; Nematollahzadeh, A. Molecularly imprinted ultrafiltration polysulfone membrane with specific nano-cavities for selective separation and enrichment of paclitaxel from plant extract. React. Funct. Polym. 2018, 126, 9-19. [CrossRef]

53. Wu, Y.; Zhao, J.; Wang, C.; Lu, J.; Meng, M.; Dai, X.; Yan, Y.; Li, C. A novel approach toward fabrication of porous molecularly imprinted nanocomposites with bioinspired multilevel internal domains: Application to selective adsorption and separation membrane. Chem. Eng. J. 2016, 306, 492-503. [CrossRef]

54. Wu, Y.; Li, C.; Meng, M.; Lv, P.; Liu, X.; Yan, Y. Fabrication and evaluation of GO/TiO2-based molecularly imprinted nanocomposite membranes by developing a reformative filtering strategy: Application to selective adsorption and separation membrane. Sep. Purif. Technol. 2019, 212, 245-254. [CrossRef]

55. Wu, X.; Wu, Y.; Chen, L.; Yan, L.; Zhou, S.; Zhang, Q.; Li, C.; Yan, Y.; Li, H. Bioinspired synthesis of pDA@GO-based molecularly imprinted nanocomposite membranes assembled with dendrites-like Ag microspheres for high-selective adsorption and separation of ibuprofen. J. Memb. Sci. 2018, 553, 151-162. [CrossRef]

56. Yan, M.; Wu, Y. Fabrication and evaluation of bioinspired pDA@TiO2-based ibuprofen-imprinted nanocomposite membranes for highly selective adsorption and separation applications. New J. Chem. 2020, 44, 10703-10712. [CrossRef]

57. Wu, Y.; Liu, X.; Cui, J.; Meng, M.; Dai, J.; Li, C.; Yan, Y. Bioinspired synthesis of high-performance nanocomposite imprinted membrane by a polydopamine-assisted metal-organic method. J. Hazard. Mater. 2017, 323, 663-673. [CrossRef] [PubMed]

58. Sun, F.; Meng, M.; Yan, L.; He, Z.; Yan, Y.; Liu, Y.; Liu, S. Fabrication of ordered microporous styrene-acrylonitrile copolymer blend imprinted membranes for selective adsorption of phenol from salicylic acid using breath figure method. J. Appl. Polym. Sci. 2015, 132, 42350. [CrossRef]

59. Odabaşı, M.; Uzun, L.; Baydemir, G.; Aksoy, N.H.; Acet, Ö.; Erdönmez, D. Cholesterol imprinted composite membranes for selective cholesterol recognition from intestinal mimicking solution. Colloids Surf. B Biointerfaces 2018, 163, 266-274. [CrossRef]

60. Niesa, J.; Ulianas, A. Design and characterization of membrane molecularly imprinted polymer (MIP) as cholesterol absorbent. J. Phys. Conf. Ser. 2020, 1481, 012031. [CrossRef]

61. Zhou, Z.; Cui, K.; Mao, Y.; Chai, W.; Wang, N.; Ren, Z. Green preparation of d-tryptophan imprinted selfsupported membrane for ultrahigh enantioseparation of racemic tryptophan. RSC Adv. 2016, 6, 109992-110000. [CrossRef]

62. Gao, B.; Cui, K.; Li, Y. Preparation of molecule imprinted membrane of single enantiomer of amino acid with an innovative strategy and study on its chiral recognition and resolution properties. J. Chem. Technol. Biotechnol. 2017, 92, 1566-1576. [CrossRef] 
63. Luo, Z.; Du, W.; Guo, P.; Zheng, P.; Chang, R.; Wang, J.; Zeng, A.; Chang, C.; Fu, Q. A porous hybrid imprinted membrane for selectively anchoring target proteins from a complex matrix. RSC Adv. 2015, 5, 72610-72620. [CrossRef]

64. Demir, E.F.; Özçalışkan, E.; Karakaş, H.; Uygun, M.; Aktaş Uygun, D.; Akgöl, S.; Denizli, A. Synthesis and characterization of albumin imprinted polymeric hydrogel membranes for proteomic studies. J. Biomater. Sci. Polym. Ed. 2018, 29, 2218-2236. [CrossRef] [PubMed]

65. Fan, J.-P.; Zhang, F.-Y.; Yang, X.-M.; Zhang, X.-H.; Cao, Y.-H.; Peng, H.-L. Preparation of a novel supermacroporous molecularly imprinted cryogel membrane with a specific ionic liquid for protein recognition and permselectivity. J. Appl. Polym. Sci. 2018, 135, 46740. [CrossRef]

66. Xie, W.; Wang, H.; Tong, W.; Sankarakumar, N.; Yin, M.; Wu, D.; Duan, X. Specific purification of a single protein from a cell broth mixture using molecularly imprinted membranes for the biopharmaceutical industry. RSC Adv. 2019, 9, 23425-23434. [CrossRef]

67. El Gharras, H. Polyphenols: Food sources, properties and applications-A review. Int. J. Food Sci. Technol. 2009, 44, 2512-2518. [CrossRef]

68. Huang, Z.; Zhang, P.; Yun, Y. Preparing molecularly imprinted membranes by phase inversion to separate kaempferol. Polym. Adv. Technol. 2017, 28, 373-378. [CrossRef]

69. Türkcan, C.; Somtürk, B.; Özdemir, N.; Özel, M.; Çatalkaya, R.; Aktaş Uygun, D.; Uygun, M.; Akgöl, S. Quercetin adsorption with imprinted polymeric materials. J. Biomater. Sci. Polym. Ed. 2019, 30, 947-960. [CrossRef]

70. He, J.; Liu, A.; Paul Chen, J. Introduction and demonstration of a novel Pb(II)-imprinted polymeric membrane with high selectivity and reusability for treatment of lead contaminated water. J. Colloid Interface Sci. 2015, 439, 162-169. [CrossRef]

71. Lu, J.; Qin, Y.; Zhang, Q.; Wu, Y.; Cui, J.; Li, C.; Wang, L.; Yan, Y. Multilayered ion-imprinted membranes with high selectivity toward $\mathrm{Li}+$ based on the synergistic effect of 12 -crown-4 and polyether sulfone. Appl. Surf. Sci. 2018, 427, 931-941. [CrossRef]

72. Lu, J.; Wu, Y.; Lin, X.; Gao, J.; Dong, H.; Chen, L.; Qin, Y.; Wang, L.; Yan, Y. Anti-fouling and thermosensitive ion-imprinted nanocomposite membranes based on grapheme oxide and silicon dioxide for selectively separating europium ions. J. Hazard. Mater. 2018, 353, 244-253. [CrossRef]

73. Kashani, T.; Jahanshahi, M.; Rahimpour, A.; Peyravi, M. Nanopore Molecularly Imprinted Polymer Membranes for Environmental Usage: Selective Separation of 2,4-Dichlorophenoxyacetic Acid as a Toxic Herbicide from Water. Polym. Plast. Technol. Eng. 2016, 55, 1700-1712. [CrossRef]

74. Söylemez, M.A.; Güven, O. Radiation induced in-situ synthesis of membranes for removal of 2,4-dichlorophenoxy acetic acid from real water samples. Radiat. Phys. Chem. 2020, 171, 108708. [CrossRef]

75. Ashrafian, S.; Ataei, S.A.; Jahanshahi, M. Novel composite membranes embedded with molecularly imprinted porous polymeric nanospheres for targeted phenol. Polym. Adv. Technol. 2016, 27, 789-804. [CrossRef]

76. Wolska, J.; Smolinska-Kempisty, K. Polypropylene prefilters with surface imprinted layer. Sep. Purif. Technol. 2017, 174, 89-96. [CrossRef]

77. Di Bello, M.P.; Mergola, L.; Scorrano, S.; Del Sole, R. Towards a new strategy of a chitosan-based molecularly imprinted membrane for removal of 4-nitrophenol in real water samples. Polym. Int. 2017, 66, 1055-1063. [CrossRef]

78. Wu, Y.; Xing, W.; Yan, J.; Cui, J.; Ma, F.; Gao, J.; Lu, J.; Yu, C.; Yan, M. Multilevel mineral-coated imprinted nanocomposite membranes for template-dependent recognition and separation: A well-designed strategy with PDA/CaCO 3 -based loading structure. J. Colloid Interface Sci. 2020, 575, 356-366. [CrossRef] [PubMed]

79. Ghasemi, S.; Nematollahzadeh, A. Molecularly imprinted polymer membrane for the removal of naphthalene from petrochemical wastewater streams. Adv. Polym. Technol. 2018, 37, 2288-2293. [CrossRef]

80. Zheng, H.; Yoshikawa, M. Molecularly imprinted cellulose membranes for pervaporation separation of xylene isomers. J. Memb. Sci. 2015, 478, 148-154. [CrossRef]

81. Abdel-Shafy, H.I.; Sayour, H.E.; Mansour, M.S.M. Molecular imprinted membrane based on molecular imprinted nanoparticles polymer for separation of polycyclic aromatic hydrocarbons. Polym. Adv. Technol. 2016, 27, 724-732. [CrossRef]

82. Mkhize, D.S.; Nyoni, H.; Quinn, L.P.; Mamba, B.B.; Msagati, T.A.M. Molecularly imprinted membranes (MIMs) for selective removal of polychlorinated biphenyls (PCBs) in environmental waters: Fabrication and characterization. Environ. Sci. Pollut. Res. 2017, 24, 11694-11707. [CrossRef] 
83. Mujahid, A.; Maryam, A.; Afzal, A.; Zafar Bajwa, S.; Hussain, T.; Imran Din, M.; Latif, U.; Irshad, M. Molecularly imprinted poly(methyl methacrylate)-nickel sulfide hybrid membranes for adsorptive desulfurization of dibenzothiophene. Sep. Purif. Technol. 2020, 237, 116453. [CrossRef]

84. Lu, L.; Yue, X.; Lin, F.; Huang, F.; Zhang, B.; Lin, Z. Template-synthesized ultra-thin molecularly imprinted polymers membrane for the selective preconcentration of dyes. J. Mater. Chem. A 2015, 3, 10959-10968. [CrossRef]

85. Melvin Ng, H.K.; Leo, C.P.; Abdullah, A.Z. Selective removal of dyes by molecular imprinted TiO2 nanoparticles in polysulfone ultrafiltration membrane. J. Environ. Chem. Eng. 2017, 5, 3991-3998. [CrossRef]

86. Zhao, J.; Wu, Y.; Zhou, S.; Yan, L.; Dong, H.; Chen, L.; Meng, M.; Li, C.; Yan, Y. Molecularly imprinted nanocomposite membranes based on GO/PVDF blended membranes with an organic-inorganic structure for selective separation of norfloxacin. New J. Chem. 2017, 41, 14966-14976. [CrossRef]

87. Xing, W.; Wu, Y.; Lu, J.; Lin, X.; Yu, C. Biomass-Based Synthesis of Green and Biodegradable Molecularly Imprinted Membranes for Selective Recognition and Separation of Tetracycline. Nano 2020, 15, 2050004. [CrossRef]

Publisher's Note: MDPI stays neutral with regard to jurisdictional claims in published maps and institutional affiliations.

(C) 2020 by the authors. Licensee MDPI, Basel, Switzerland. This article is an open access article distributed under the terms and conditions of the Creative Commons Attribution (CC BY) license (http://creativecommons.org/licenses/by/4.0/). 